\title{
Morphological evolution of block copolymer nanocomposites submitted to extensional flows
}

\author{
Leice G. Amurin \\ Mechanical Engineering Department, École de Technologie Supérieure (ETS), Montreal, Québec H3C 1 K3, \\ Canada and Metallurgical and Materials Engineering Department, Escola Politécnica, University of São Paulo, \\ São Paulo, Brazil \\ Danilo J. Carastan \\ Center for Engineering, Modeling and Applied Social Sciences, Federal University of ABC (UFABC), Santo André, \\ São Paulo, Brazil \\ Nicole R. Demarquette ${ }^{\text {a) }}$ \\ Mechanical Engineering Department, École de Technologie Supérieure (ETS), Montreal, Québec H3C 1 K3, Canada
}

(Received 1 July 2015; final revision received 22 November 2015; published 30 December 2015)

\begin{abstract}
In this work, the effect of extensional flow on the morphology of polystyrene- $b$-poly(ethylene-co-butylene)- $b$-polystyrene (SEBS) triblock copolymers and their clay-containing nanocomposites was evaluated. Four types of SEBS copolymers with different block compositions and cylindrical morphology were chosen to understand the effects of cylinder orientation and state of clay dispersion on the evolution of morphology during extensional flow. The effect of clay concentration (ranging from 2.5 to $7.5 \mathrm{wt}$. \%) was also studied. The samples were subjected to extensional flow using a Sentmanat extensional rheometer attached to a rotational rheometer at Hencky strain rates varying from 0.01 to $20 \mathrm{~s}^{-1}$. Small angle X-ray scattering analysis was subsequently performed to evaluate the morphological changes caused by extensional flow. When preoriented block copolymers [SEBS-30\% PS (polystyrene)] and their nanocomposites undergo elongation, the styrene cylinders and clay nanoparticles align themselves in the flow direction and their rheological behavior and morphological evolution are influenced by the stretching direction (longitudinal and transverse), strain rate magnitude, clay concentration, and dispersion state of the clay nanoparticles. When isotropic block copolymers (SEBS-13\% PS) undergo elongation, it was observed that the PS cylinders only exhibit structural alignment in the stretching direction in the presence of clay. Block copolymer molecules can exhibit different relaxation times depending upon the volume fraction of PS domains (13\% or 30\%). The addition of clay, however, hinders complete relaxation, helping to promote a permanent domain alignment after flow cessation, especially in hard-to-align copolymers. (C) 2016 The Society of Rheology.

[http://dx.doi.org/10.1122/1.4938278]
\end{abstract}

\section{INTRODUCTION}

Block copolymers are materials that can be used in several applications due to their molecular characteristics. Their molecules are composed of blocks usually immiscible with each other, resulting in phase-separated structures at the nanometer level. According to the thermodynamic affinity between the blocks of a copolymer, as well as their absolute and relative length, block copolymers can present different types of morphologies, the most common ones being the spherical, lamellar, and cylindrical structures [1-6]. In particular, styrenic block copolymers such as polystyrene- $b$-polyisoprene- $b$-polystyrene (SIS) and polystyrene- $b$-poly(ethylene-co-butylene)- $b$-polystyrene triblock copolymers (SEBS) have drawn the attention of the industry, as they can be used as thermoplastic elastomers (TPE) due

\footnotetext{
a) Author to whom correspondence should be addressed; electronic mail: nicoler.demarquette@etsmtl.ca

to their structure composed of immiscible rigid (styrene) and flexible blocks (such as ethylene-co-butylene (EB), butadiene, or isoprene) [7-9].

More recently, these materials have gained attention for a different reason, as they can present piezoelectric properties [10-12], and thus can be used as sensors, actuators for artificial muscles, and other applications [13-16]. Whether block copolymers are used for their mechanical or electrical properties, there is a need to control their morphology [17]. In the case of a block copolymer with a certain chemical structure and molecular weight, this control can be achieved during processing and through the addition of well-tailored nanoparticles [18-22]. In particular, the morphology of block copolymers can be controlled by subjecting them to shear or extensional flows. Moreover, the addition of nanoparticles can induce morphological changes on a block copolymer, depending on the chemical affinity between the nanoparticles and the different domains present in the copolymer [23-26].

Few studies have been published regarding the morphological evolution of block copolymer nanocomposites above 
the glass transition temperature of the hard domains, especially when the block copolymers are subject to extensional flows at high Hencky strain rates. Burghardt et al. [27,28] studied the morphological evolution of SEBS block copolymers containing $13 \mathrm{wt}$ \% PS blocks, using a uniaxial elongation device attached to a small angle X-ray scattering (SAXS) line. They revealed details about structural changes of the polymeric chains such as the structural deformation and rotation of the PS domains in the stretching direction. As the structural relaxation time was very small, the PS domain alignment was not maintained after extensional flow cessation.

Aiming at future applications, tailoring the morphology of these copolymers by avoiding such relaxation processes is important to keep the structural alignment after flow cessation. One strategy is to evaluate how the presence of nanoparticles affects the final morphology. Very few works have been published focusing on the rheological behavior and morphological changes in block copolymer nanocomposites under extensional flow. In a previous work, we evaluated the effects of extensional flow on the morphology of SEBS copolymers containing $30 \mathrm{wt}$. \% PS domains, which presented a cylindrical structure, and on the morphology of their nanocomposites containing $5 \mathrm{wt}$. \% clay [29]. Both the cylinders and the clay particles were initially aligned by extrusion, and the samples were tested in uniaxial extensional flow in directions parallel and perpendicular to the axis of the PS cylinders [29]. When the materials were tested in the direction of extrusion (direction of flow parallel to the axis of the cylinders), the copolymers and nanocomposites behaved according to Trouton's rule and the clay particles did not seem to affect the rheological behavior of the block copolymers. When the materials were tested in a direction perpendicular to the cylinders, the materials exhibited strain softening followed by strain hardening. In that case, the presence of clay affected the rheological behavior of the copolymers. SAXS experiments revealed that the cylindrical domains and clay nanoparticles tend to align in the drawing direction regardless of previous cylinder and clay orientation. The magnitude and speed of alignment of the cylinders and clay particles were shown to depend on the Hencky strain rate and state of clay dispersion: exfoliated clay nanoparticles forming a network probably hindered cylinder alignment, while intercalated clay nanoparticles within the cylinders probably caused the opposite effect, enhancing the alignment of the cylindrical domains. The orientation of the nanostructure was shown to be affected by a competition between the relaxation of the block copolymer molecules and hydrodynamic effects promoted by the clay nanoparticles.

In order to complement the observations obtained by Carastan et al. [29], other samples with different clay concentrations and nonoriented (isotropic) domains were obtained and tested in the present work. Four types of block copolymers were used, all presenting a morphology of cylindrical styrene blocks within an EB matrix, but containing different fractions of polystyrene blocks (13 and $30 \mathrm{wt}$. \%). While the copolymers containing $30 \mathrm{wt}$. \% PS were aligned during extrusion, those containing $13 \mathrm{wt}$. \% presented an isotropic morphology after processing. The effect of clay concentration (varying from 2.5 to $7.5 \mathrm{wt}$. \%) on the morphological evolution of the samples containing $30 \mathrm{wt}$. $\%$ PS was also studied. After characterization by X-ray diffraction (XRD) and SAXS to determine the nanocomposites structure and orientation induced during processing, the samples were subjected to extensional flow using a Sentmanat extensional rheometer [30] (SER) coupled to a rotational rheometer and their morphology was studied by SAXS after elongation.

\section{EXPERIMENTAL}

\section{A. Materials and processing}

\section{Materials}

Four SEBS block copolymers supplied by Kraton Polymers were used. The characteristics of the copolymers are shown in Table I. All samples presented morphology of PS cylinders within the EB phase, as shown further in this work. The molecular weight was determined by gel permeation chromatography (GPC) in THF (tetrahydrofuran) solution using Viscotek HT-GPC (350A) equipment. The organoclay used in this study was a commercial montmorillonite Cloisite 20A modified with a quaternary ammonium salt, supplied by Southern Clay Products, Inc (Gonzales, USA).

a. Processing. The copolymers and their nanocomposites were melt processed in a Haake Rheomix PTW-16 double-screw extruder attached to a Thermo Haake PolyLab 900 torque rheometer, using a ribbon die 55-2301 having a $25 \mathrm{~mm}$ width and $1 \mathrm{~mm}$ thickness. The processing conditions were $150^{\circ} \mathrm{C}$ (SEBS-13 and SEBS-13-MA) and $220^{\circ} \mathrm{C}$ (SEBS-30 and SEBS-30-MA) in the six temperature zones of the extruder and screw speed of $100 \mathrm{rpm}$. Details of the preparation technique were reported in a previous related work [26].

TABLE I. Properties of the SEBS block copolymers.

\begin{tabular}{|c|c|c|c|c|c|c|}
\hline Polymer & Grade & wt. \% PS & $\mathrm{M}_{\mathrm{w}}(\mathrm{g} / \mathrm{mol})$ & $\mathrm{M}_{\mathrm{n}}(\mathrm{g} / \mathrm{mol})$ & $\mathrm{M}_{\mathrm{w}} / \mathrm{M}_{\mathrm{n}}$ & Clay concentration (wt. \%) \\
\hline SEBS-30 & G1652 & 30 & 73000 & 68000 & 1.08 & $2.5,5,7.5$ \\
\hline SEBS-30-MA ${ }^{a}$ & FG1901 & 30 & 77000 & 44000 & 1.74 & $2.5,5,7.5$ \\
\hline SEBS-13 & G1645 & 13 & 122000 & 85000 & 1.43 & 5 \\
\hline SEBS-13-MA ${ }^{\mathrm{b}}$ & FG1924 & 13 & 127000 & 87000 & 1.46 & 5 \\
\hline
\end{tabular}

${ }^{\text {a }}$ Contains $1 \%-2 \%$ maleic anhydride grafted in the PEB phase.

${ }^{\mathrm{b}}$ Contains $0.7 \%-1.3 \%$ maleic anhydride grafted in the PEB phase. 


\section{B. Characterization}

\section{Structural and morphological characterization of the block copolymers and nanocomposites}

a. Small-angle X-ray scattering. The morphology of the block copolymers and nanocomposites before and after extensional deformation was evaluated by SAXS. The tests were carried out using the synchrotron source of the National Synchrotron Light Laboratory (LNLS), Campinas, Brazil, with an X-ray wavelength of $1.488 \AA$ and a sampleto-detector distance of $950 \mathrm{~mm}$ and also using a Bruker NanoSTAR equipped with $1.5 \mathrm{kV} \mathrm{CuK} \alpha$ radiation and a sample-to-detector distance of $650 \mathrm{~mm}$. The data were processed using the software Fit2D. Bidimensional detectors were used in order to evaluate anisotropic features of the samples. Corresponding 1D SAXS curves were plotted as a function of the scattering vector $q$ from the integration of 2D patterns over a sector covering an azimuthal angle range between $60^{\circ}$ and $90^{\circ}$, depending on the sample.

b. X-ray diffraction. The clay interlayer distance was evaluated by XRD, using an X'Pert PRO Diffractometer detector X'Celerator, with a $40 \mathrm{kV}, 40 \mathrm{~mA} \mathrm{CuK} \alpha$ source. The $\mathrm{x}$-ray beam scanned angles ranging from $1.15^{\circ}$ to $10^{\circ}$ at a $0.05^{\circ}$ step. The samples (clay and nanocomposites) were analyzed in powder form, which was obtained after grinding the samples previously frozen in liquid nitrogen.

c. Transmission electron microscopy. Transmission electron microscopy (TEM) was performed with a Carl Zeiss CEM 902 transmission electron microscope for the SEBS30 . The samples were cut into ultrathin slices $(40-60 \mathrm{~nm}$ thick) using an ultramicrotome at $-100{ }^{\circ} \mathrm{C}$. The slices were stained for $30 \mathrm{~min}$ with $\mathrm{RuO}_{4}$ vapor in order to reveal the block copolymer morphology, as $\mathrm{RuO}_{4}$ stains preferentially the PS domains preferentially.

\section{Rheological measurements}

Different techniques can be used to study the rheological behavior under extensional flow [31-34]. In the present work, the samples were subjected to extensional flow using an SER geometry [35] coupled to an ARES rheometer controlled strain rheometer from TA instruments. The SER geometry consists of two rolls rotating in opposite directions. Rectangular samples are fixed to each roll and due to the stretching created by the roll motion at the same angular velocity, a tangential force is generated and consequently a uniform extensional deformation is applied along the specimens. The extensional viscosity $\left(\eta_{\mathrm{E}}{ }^{+}\right)$can then be calculated by knowing the resistance to the deformation. Rectangular samples with dimensions of $(20 \times 6 \times 1) \mathrm{mm}$ were cut from the extruded strips in directions parallel [longitudinal direction (L)] and perpendicular [transverse direction (T)] to the extrusion direction. Figure 1 presents the directions and dimensions of the extruded ribbon samples. Rheological tests in extensional flow, for the samples containing 13 and $30 \mathrm{wt}$. \% PS, were carried out at 120 and $200^{\circ} \mathrm{C}$, respectively. The temperatures were chosen in order to maintain the morphological structure after extrusion. Four strain rates were applied to the samples: $0.01,0.1,1$, and $20 \mathrm{~s}^{-1}$. Steady shear tests were also

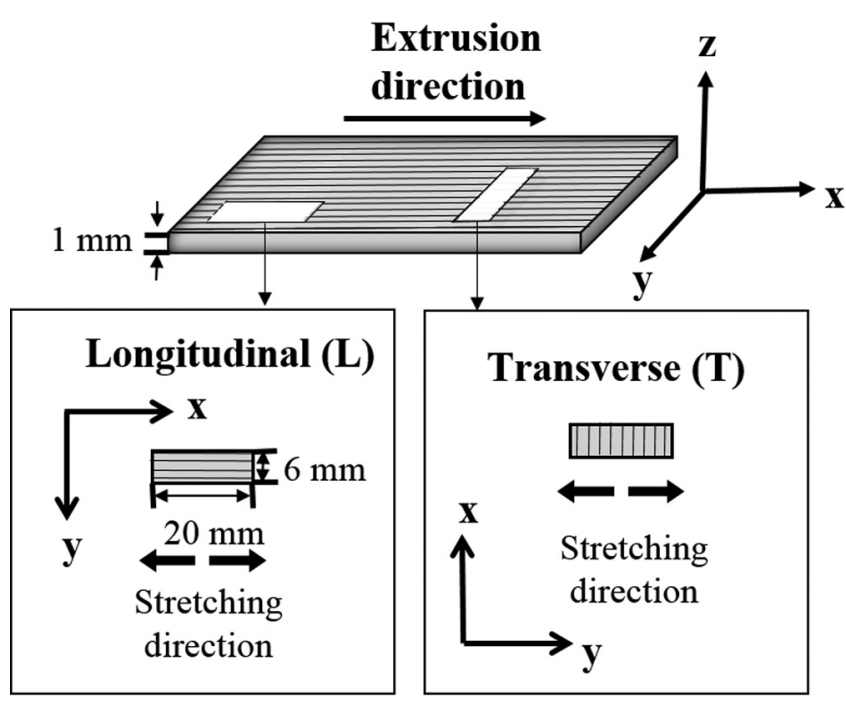

FIG. 1. Scheme shows how the specimens were cut for the extensional tests from tape samples obtained by melt extrusion: $\mathrm{x}$ is the direction parallel to the extrusion flow, $y$ is the direction perpendicular to the extrusion flow, and $\mathrm{z}$ is perpendicular to the tape plane.

carried out on some samples using a $25 \mathrm{~mm}$ rotational geometry. These samples were prepared by compression molding at $20{ }^{\circ} \mathrm{C}$, being molded into $25 \times 1 \mathrm{~mm}$ disks.

After the rheological tests, just after the failure, the samples were cooled down to room temperature using a compressed air jet. The cooled samples were then analyzed at different spots along the deformed samples following the procedures reported in Carastan et al. [26]. The position of the different spots corresponded to different Hencky strains, as can be seen in Fig. 2.

The Hencky strain $(\varepsilon)$ of each spot analyzed $\left(\mathrm{u}_{\mathrm{i}}\right)$ was calculated by the following Eq. (1)

$$
\varepsilon=\ln \left[\frac{\left(\Delta \mathrm{u}_{\mathrm{i} 0}+6.36\right)}{6.36}\right]
$$

where $\Delta \mathrm{u}_{\mathrm{i} 0}$ represents the difference between the analyzed deformation point $\left(\mathrm{u}_{\mathrm{i}}\right)$ and zero deformation $\left(\mathrm{u}_{0}\right)$. The value $6.36 \mathrm{~mm}$ is half of the distance between the axis of the SER geometry rolls.

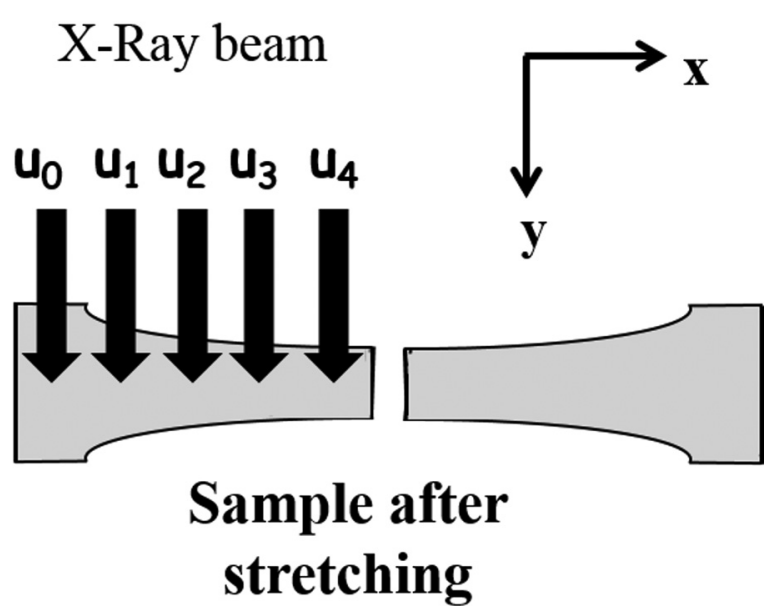

FIG. 2. Scheme of the specimens analyzed by SAXS after the extensional test. 


\section{Dynamic mechanical analysis}

Dynamic mechanical analysis (DMA) was done using a Q800 DMA from TA Instruments in tensile mode. Rectangular samples of $20 \times 6.5 \times 1 \mathrm{~mm}$ were cut from the extruded strips in directions parallel [longitudinal direction (L)] and perpendicular [transverse direction (T)] to the extrusion direction, as shown in Fig. 1. The samples were tested in oscillating mode, being heated from -100 to $140^{\circ} \mathrm{C}$ at a $5^{\circ} \mathrm{C} / \mathrm{min}$ rate. The oscillation frequency was set at $1 \mathrm{~Hz}$ and the amplitude was $0.2 \mu \mathrm{m}$. The tensile storage modulus $\left(\mathrm{E}^{\prime}\right)$ and loss modulus $\left(\mathrm{E}^{\prime \prime}\right)$ were evaluated.

\section{RESULTS AND DISCUSSION}

\section{A. Morphology characterization}

The morphological characterization of the samples will be discussed in two parts. First, the state of clay dispersion assessed by XRD will be presented. Then, the results of the SAXS analysis of the block copolymers prior to rheological tests and the influence of the addition of clay on the copolymer structure will be reported.

\section{Clay nanostructure}

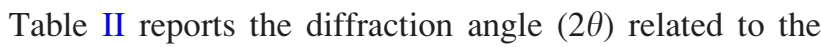
(001) plane of the clay, the basal spacing $\left[\mathrm{d}_{(001)}\right]$ and the basal spacing variation after clay being added to the nonmaleated copolymers $\left[\Delta \mathrm{d}_{(001)}\right]$. It can be seen that for all the composites the interlayer distance between the clay platelets increased about $1 \mathrm{~nm}$, indicating that polymeric chains were intercalated between clay multilayers. It can also be seen that the interlayer distance between the clay platelets decreases as a function of clay concentration (SEBS$30+20 \mathrm{~A})$. This result can be in parts due to the effect of a partial exfoliation, which is common to this type of SEBS nanocomposite [36]. Especially at lower clay concentrations the clay tactoids are very small, and the combination of partial exfoliation and disordered intercalation can shift the diffraction peaks to lower Bragg angles [37].

The results corroborate the works previously reported $[25,26]$ who studied the state of clay dispersion in triblock copolymers. Clay particle surfaces were shown to have higher interaction with the PS chains, which exhibit a mild polarity, necessary to promote the intercalation into the clay galleries, which are also slightly polar, despite the presence of the double-tailed apolar ammonium cations [38].

The XDR patterns (not shown) for maleated SEBS nanocomposites did not exhibit any diffraction peak, indicating the probable formation of exfoliated structures. Exfoliation

TABLE II. Diffraction angle of the basal plane (20), clay interlayer spacing $\left[\mathrm{d}_{(001)}\right]$ and variation of the clay spacing in the nanocomposites $\left[\Delta \mathrm{d}_{(001)}\right]$.

\begin{tabular}{lccc}
\hline \hline Samples & $2 \theta(\mathrm{deg})$ & $\mathrm{d}_{(001)}(\mathrm{nm})$ & $\Delta \mathrm{d}_{(001)}(\mathrm{nm})$ \\
\hline SEBS-30+20A (2.5 wt. \%) & 2.37 & 3.73 & 1.27 \\
SEBS-30+20A (5 wt. \%) & 2.49 & 3.55 & 1.09 \\
SEBS-30+20A (7.5 wt. \%) & 2.55 & 3.47 & 1.01 \\
SEBS-13+20A (5 wt. \%) & 2.54 & 3.47 & 1.01 \\
Clay (Cloisite 20A) & 3.58 & 2.46 & - \\
\hline \hline
\end{tabular}

may have occurred due to the better affinity between the maleated groups and the clay, as discussed in previous studies [26].

\section{Morphological structure of block copolymers}

Figure 3 shows 1D SAXS plots obtained with the X-ray beam parallel to the $\mathrm{z}$ direction (perpendicular to the tape plane, as shown in Fig. 1). Samples were tested in three different clay concentrations, but 1D SAXS curves are shown only for samples containing $5 \mathrm{wt}$. \% clay, because in this study clay concentration does not interfere in the morphological structure of the block copolymers. It can be seen that in 1D SAXS plots no changes were observed in the features of the patterns upon clay addition. Bragg peak maxima appear at angles for which the ratios $\mathrm{q}_{\mathrm{n}} / \mathrm{q}_{1}$ are equal to $1, \sqrt{ } 3, \sqrt{ } 7$, and $\sqrt{9}$, indicating that the pure copolymers and their nanocomposites present similar cylindrical hexagonal structures. It can be also seen from Fig. 3(b) that the peak sequences for SEBS-13 and SEBS-13-MA are less defined than the ones
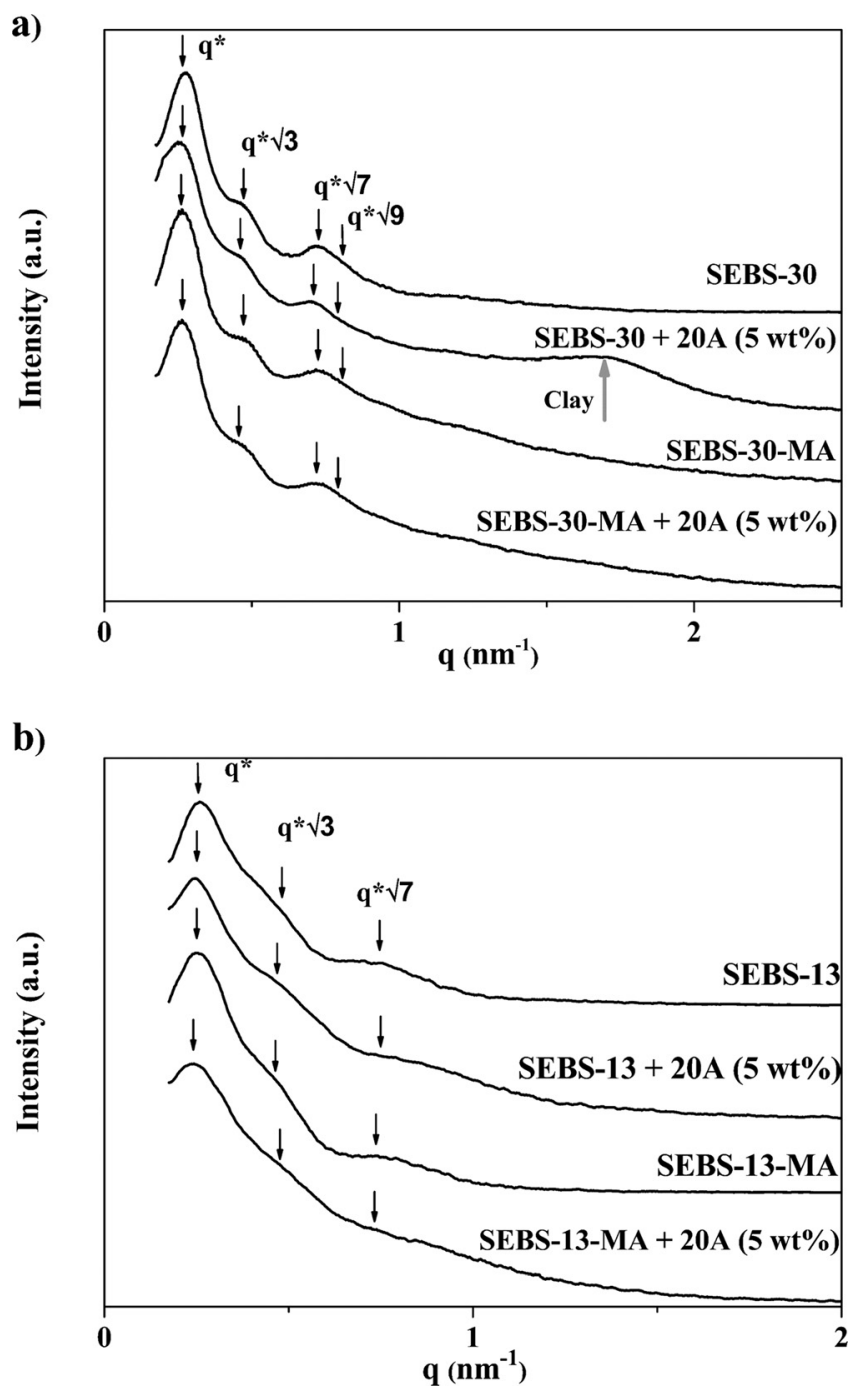

FIG. 3. 1D SAXS plots [intensity I(q) vs scattering vector, q obtained by SAXS patterns for pure copolymers and nanocomposites]. (a) SEBS-30 and SEBS-30-MA and its nanocomposites (5 wt. \% clay concentration) and (b) SEBS-13/0, SEBS-13/0-MA and their nanocomposites ( $5 \mathrm{wt}$ \% clay concentration). 
for SEBS-30 copolymers. This could be an indication of a poorer long-range order of the PS cylinders, once PS blocks are shorter for SEBS-13 copolymers.

A small peak at a value of $q$ of roughly $1.8 \mathrm{~nm}^{-1}$ can be observed for the SEBS-30+20 A (5 wt. \%) nanocomposite. This peak corresponds to the diffraction of the clay platelets, which are intercalated in this sample. Such a peak cannot be observed in the case of SEBS-13+20A, most likely due to the fact that the clay platelets were oriented parallel to the $\mathrm{x}$-y plane, which was perpendicular to the x-ray beam during the observation, as will be shown later.

Using the value of the first Bragg peak $\left(q^{*}\right)$, it was possible to calculate the distance between the (100) planes of the cylindrical structure $\left[\mathrm{d}_{(100)}\right]$. Table III presents these values for all the systems studied here. It can be seen that the values of $\mathrm{d}_{(100)}$ for the copolymers containing $30 \mathrm{wt}$. \% PS are around 22.5 and $23.5 \mathrm{~nm}$ (SEBS-30 and SEBS-30-MA), whereas those for SEBS containing $13 \mathrm{wt} \%$ are around $24 \mathrm{~nm}$, being all similar values. It can also be observed that upon clay addition the distance between the styrene cylindrical domains had a small increase $\left[\Delta \mathrm{d}_{(100)}\right]$. This increase was much larger for the samples that did not contain maleic anhydride grafted to the EB block. A possible explanation is that clay stacks usually try to maximize their contact with PS domains in nonmaleated samples, whereas the presence of MA in EB blocks favors the dispersion and exfoliation of clay particles within the EB matrix.

In order to evaluate the alignment of the cylinder domains and clay nanoparticles, SAXS analysis of the copolymer and composite samples after extrusion was performed in the $\mathrm{x}, \mathrm{y}$, and $\mathrm{z}$ directions, according to Fig. 1 .

For the pure block copolymers, two different behaviors were observed. Figure 4 shows the 2D SAXS patterns obtained for the copolymers containing $30 \mathrm{wt}$. \% PS [Fig. 4(a)] and 13 wt. \% PS [Fig. 4(b)]. In this example, only the SAXS patterns for SEBS-30-MA and for SEBS-13 are shown, but the results are similar for other copolymers with the same amount of PS. In the case of the SEBS-30 copolymers, the 2D SAXS patterns indicate that the PS cylinders are aligned parallel to the extrusion flow after processing.

TABLE III. Average distance between the (100) planes of the cylindrical structure $\left[\mathrm{d}_{(100)}\right]$ calculated from the SAXS results. $\Delta \mathrm{d}_{(100)}$ is the difference between $\mathrm{d}_{(100)}$ of the nanocomposites and their respective pure copolymers.

\begin{tabular}{lcc}
\hline \hline Samples & $\mathrm{d}_{(100)}(\mathrm{nm})$ & $\Delta \mathrm{d}_{(100)}(\mathrm{nm})$ \\
\hline SEBS-30 & 22.54 & $*^{\mathrm{a}}$ \\
SEBS-30-MA & 23.51 & $*^{\mathrm{a}}$ \\
SEBS-13 & 24.03 & $*^{\mathrm{a}}$ \\
SEBS-13-MA & 24.52 & $*^{\mathrm{a}}$ \\
SEBS-30+20A (2.5\%) & 22.86 & 0.32 \\
SEBS-30+20A (5\%) & 24.72 & 2.18 \\
SEBS-30+20A (7.5\%) & 25.04 & 2.50 \\
SEBS-30-MA+20A (2.5\%) & 23.94 & 0.43 \\
SEBS-30-MA+20A (5\%) & 24.16 & 0.65 \\
SEBS-30-MA+20A (7.5\%) & 24.18 & 0.67 \\
SEBS-13+20A (5\%) & 25.08 & 1.05 \\
SEBS-13-MA+20A (5\%) & 24.75 & 0.23 \\
\hline \hline
\end{tabular}

a“**” not applicable.
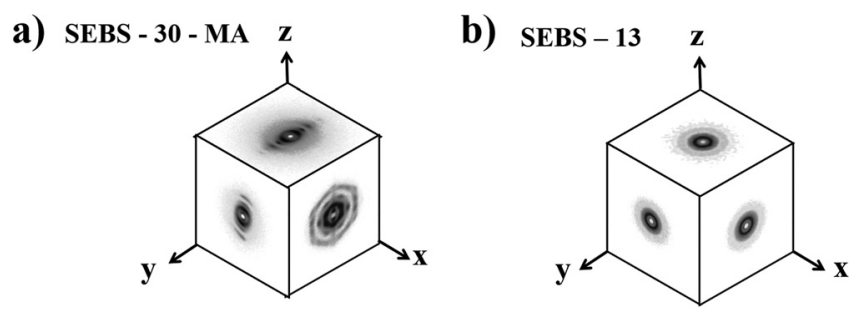

FIG. 4. 2D SAXS patterns of extruded copolymer ribbons containing 13 and 30 wt. \% PS in the directions $x, y$, and $z$, as defined in Fig. 1: (a) SEBS-30MA and (b) SEBS-13.

The 2D SAXS pattern corresponding to the $\mathrm{x}$-axis direction also reveals that the cylinders are arranged almost in a single crystal-like structure due to the shear occurring in a die with planar geometry. These results corroborate the ones we obtained previously [26]. In the case of the SEBS-13 copolymers, the 2D SAXS patterns are similar in all three directions, exhibiting concentric circles indicating that the PS cylinders were not aligned during the extrusion process. This is probably due to the lower viscosity of these copolymers, and the smaller fraction of PS blocks.

The presence of clay adds distinctive features to the 2D SAXS patterns of the nanocomposites. Figures $5(\mathrm{a})$ and $5(\mathrm{~b})$ present SAXS patterns for SEBS-13+20A and SEBS-13$\mathrm{MA}+20 \mathrm{~A}$ in the $\mathrm{x}, \mathrm{y}$, and $\mathrm{z}$ directions. The patterns for SEBS13+20A reveal a set of halos/spots marked as $C_{1}$ in Fig. 5(a), which correspond to the Bragg peaks associated with the layers of the clay stacks. The maxima of these halos are aligned in the $\mathrm{z}$ direction, indicating that the clay platelets are parallel to the $x-y$ plane, which contains the extrusion direction $x$. A different pattern is seen for SEBS-13$\mathrm{MA}+20 \mathrm{~A}$, as no sharp Bragg peak from the clay nanoparticles can be identified, probably because they are dispersed individually within the matrix. However, the scattering pattern indicates that even these particles lie parallel to the plane of the tape, as their maximum scattering intensities are parallel to the z-axis, indicating that most of the clay platelets are parallel to the $x-y$ plane, along the extrusion direction. It should be noted that the presence of clay did not enhance the alignment of PS cylinders, and as a result they remain isotropic despite the alignment of the clay. On the other hand, the addition of clay to SEBS-30 and SEBS-30MA resulted in the formation of nanocomposites with an aligned morphology (results not shown), where the cylinders were oriented in the direction of extrusion, and most clay a)

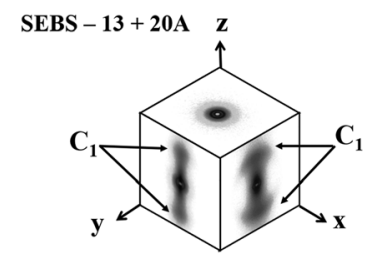

b)

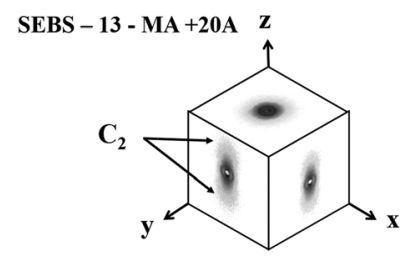

FIG. 5. 2D SAXS patterns of extruded SEBS 13 wt. \% PS nanocomposite ribbons in the directions $x, y$, and $z$, as defined in Fig. 1: (a) SEBS-13+20A and (b) SEBS-13-MA+20A. C1: halos/spots corresponding to the Bragg peaks associated to clay stacks and $\mathrm{C} 2$ : $\mathrm{x}$-ray scattering promoted by exfoliated clay nanoparticles. 
TABLE IV. Summary of the morphologies of each sample.

\begin{tabular}{|c|c|c|c|}
\hline \multirow[b]{2}{*}{ Samples } & \multicolumn{3}{|c|}{ Morphological structure } \\
\hline & PS phase & Clay dispersion & Illustration of the morphological structure \\
\hline SEBS-30+20A & $\begin{array}{l}\text { Cylindrical hexagonal } \\
\text { structure and long-range order }\end{array}$ & $\begin{array}{l}\text { Clay nanoparticles are } \\
\text { located mostly in PS phase. } \\
\text { Intercalated structure } \\
\text { Higher clay concentration } \\
\text { results in smaller interlayer } \\
\text { distance }\end{array}$ & \\
\hline SEBS-30-MA+20A & $\begin{array}{l}\text { Cylinders are aligned } \\
\text { in extrusion direction }\end{array}$ & $\begin{array}{l}\text { Clay nanoparticles are } \\
\text { located in rubbery phase } \\
\text { Exfoliated structure }\end{array}$ & \\
\hline SEBS-13+20A & $\begin{array}{l}\text { Cylindrical hexagonal } \\
\text { structure and short-range order }\end{array}$ & $\begin{array}{l}\text { Clay nanoparticles are aligned } \\
\text { in extrusion direction and present } \\
\text { alignment in a single plane } \\
\text { Intercalated structure }\end{array}$ & \\
\hline SEBS-13-MA+20A & $\begin{array}{l}\text { The cylinders do not } \\
\text { exhibit a preferential orientation }\end{array}$ & $\begin{array}{c}\text { Clay nanoparticles are aligned } \\
\text { similarly to SEBS- } 13 / 0+20 \mathrm{~A} \\
\text { Exfoliated structure }\end{array}$ & \\
\hline
\end{tabular}

nanoparticles were also aligned parallel to the $x-y$ plane (the plane of the ribbon). Just like in their $13 \mathrm{wt}$. \% PS counterparts, SEBS-30 nanocomposite exhibited an intercalated structure, whereas in SEBS-30-MA the resulting morphology was exfoliated, due to the presence of maleic anhydride. More details in the description of the morphology of these samples can be found in [26]. Table IV presents summary of the morphologies of the samples studied in this work after extrusion.

The results presented here show that all the samples studied presented a morphology of PS cylinders within a rubbery matrix. The main difference between the copolymers containing 13 and 30 wt. \% PS relied on the size of the cylinders and their differences in cylinder orientation. The $13 \mathrm{wt}$ \% PS samples did not present a preferential alignment of the cylinders, not even in the presence of clay. In the rest of the paper, an investigation will be performed to see if a stronger extensional flow alters the morphology obtained by extrusion.

\section{B. Rheological properties in extensional flow}

The samples characterized above were subjected to extensional flow at various strain rates. The evolution of the morphological structure during stretching was accessed by SAXS. In particular, the effect of the cylindrical alignment and stretching direction, as well as the clay state of dispersion and clay concentration were evaluated. The rheological behavior of different samples is presented, followed by the results of morphological evolution.

\section{Copolymers with anisotropic structure}

Figure 6 presents the tensile stress growth coefficient for SEBS 30 wt. \% PS and nanocomposites subjected to longitudinal (L) elongation (as shown in Fig. 1), at three strain rates $\left(0.01,0.1\right.$, and $\left.20 \mathrm{~s}^{-1}\right)$. Here, only data for SEBS-30MA nanocomposites containing $0,2.5,5$, and $7.5 \mathrm{wt}$. \% clay are shown. The data for the nonmaleated copolymer (SEBS30) are similar to those from SEBS-MA. In Fig. 6, the triple of the shear stress growth coefficient curve $\left(3 \cdot \eta^{+}\right)$is also plotted for the pure block copolymer and a nanocomposite (7.5 wt. \%), at $\dot{\gamma}=0.001 \mathrm{~s}^{-1}$. It can be seen that for the pure copolymer in the longitudinal direction Trouton's rule generally holds up to the onset of failure of the samples tested in elongation. Upon addition of clay, the shear linear viscosity $\left(3 \eta^{+}\right)$increased in a large order of magnitude. Such an increase was not observed for the extensional viscosity of

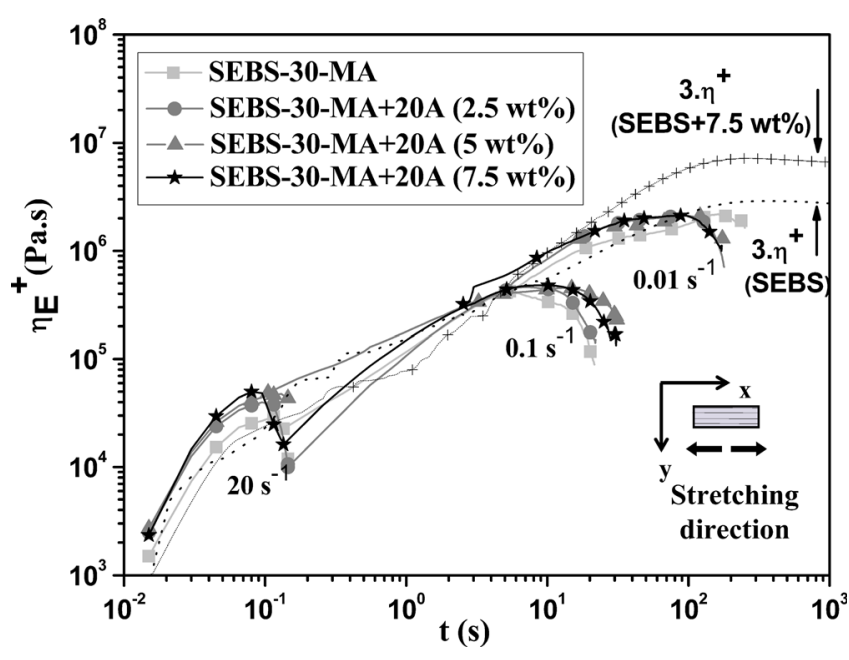

FIG. 6. Curves of the tensile stress growth coefficient tested at $200^{\circ} \mathrm{C}$ along the longitudinal direction for SEBS-30-MA nanocomposites, at three Hencky strain rates $\left(0.01,0.1,20 \mathrm{~s}^{-1}\right)$. The triple of the shear stress growth coefficient curves is indicated by $\left(3 \cdot \eta^{+}\right)$for SEBS-30 and SEBS-30+20A (7.5 wt. \%). 
the nanocomposites tested in the $\mathrm{L}$ direction. This can be explained by the preferential orientation of the clay and PS cylinders in the $\mathrm{L}$ direction. As the samples are stretched in the same direction of the clay, the addition of nanoparticles does not have a significant effect. However, in the case of shear flow, the rotational geometry makes clay particles and PS cylinders deviate from their original alignment, so they exhibit more interaction with each other, increasing the overall viscosity of the system.

Figure 7 presents the tensile stress growth coefficient $\left(\eta_{\mathrm{E}}{ }^{+}\right)$as a function of time for SEBS-30, SEBS-30-MA, and their nanocomposites tested in the transverse $(\mathrm{T})$ direction. The results are shown at four Hencky strain rates $(0.01,0.1$, 1 , and $\left.20 \mathrm{~s}^{-1}\right)$ for three clay concentrations $(2.5,5$, and $7.5 \mathrm{wt} . \%$ ). The samples elongated in the transverse direction exhibit extension thinning for all strain rates, except $20 \mathrm{~s}^{-1}$, which is characterized by a primary drop/plateau in the $\eta_{\mathrm{E}}{ }^{+}$ curves. Note that in the transverse direction the $\eta_{\mathrm{E}}{ }^{+}$plots exhibit a three step behavior as a function of time. In the first step, the tensile stress growth coefficient increases up to Hencky strain values between 0.1 and 0.3 , which
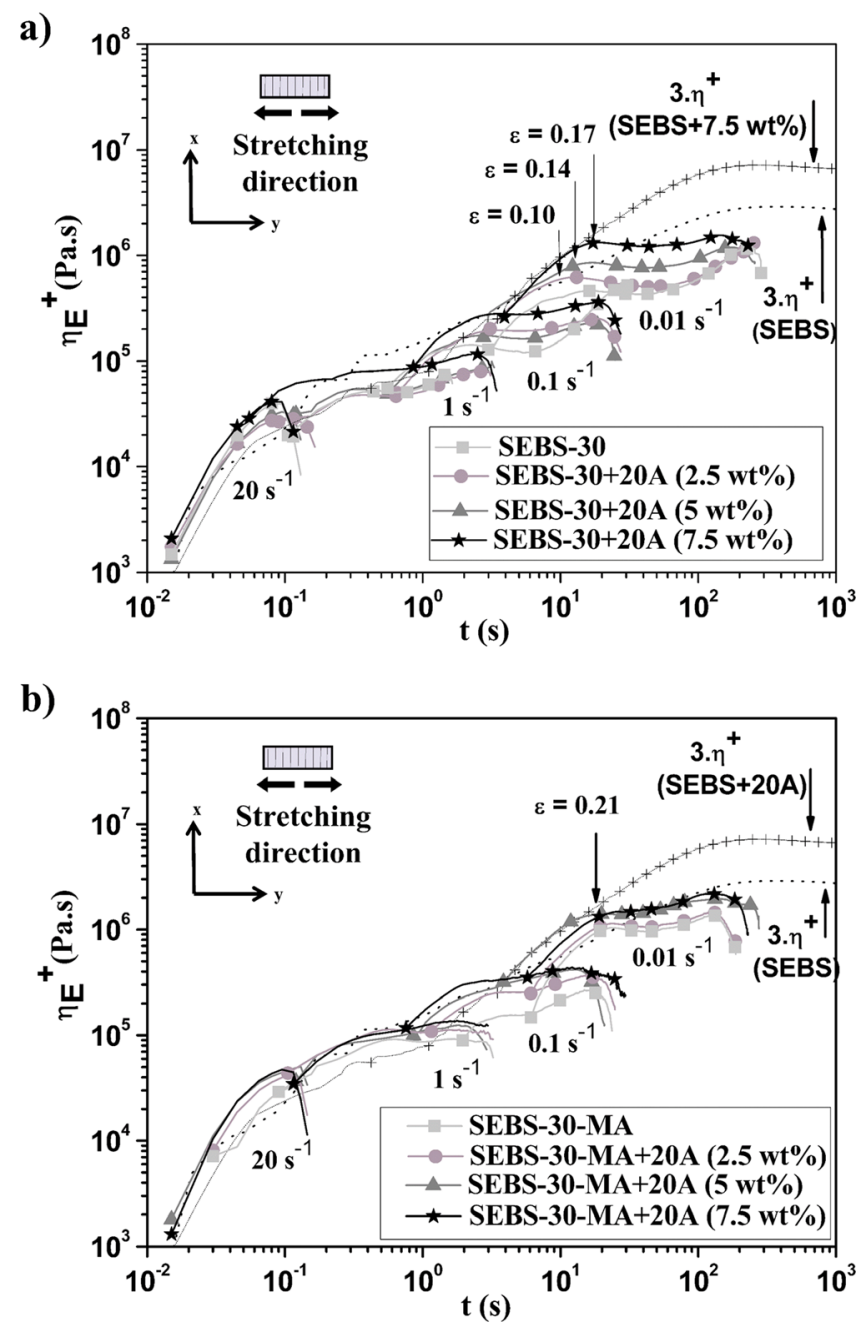

FIG. 7. Curves of the tensile stress growth coefficient tested at $200^{\circ} \mathrm{C}$ along the transverse direction: (a) SEBS-30 nanocomposites and (b) SEBS-30-MA nanocomposites. Samples were tested at four Hencky strain rates $(0.01,0.1$, $\left.1,20 \mathrm{~s}^{-1}\right)$. The triple of the shear stress growth coefficient curves is indicated by $(3 \cdot \eta+)$ for SEBS-30 and SEBS-30+20A (7.5 wt. \%). correspond to deformation of the PEB [poly(ethylene-cobutylene)] domains without any significant morphological change [27]. The second step is an extensional viscosity decrease/plateau in the strain range $0.1<\varepsilon<1$, which is the main region where occurs strain softening and the morphological changes initiate. At the final step $\eta_{\mathrm{E}}{ }^{+}$increases again up to around $\varepsilon=1$, which corresponds to the completion of morphological changes and onset of sample rupture. Due to the extension thinning effect Trouton's rule does not hold in the transverse direction.

It can also be seen that in the case of the nonmaleated copolymer (SEBS-30), the addition of clay seemed to have a greater effect on the tensile stress growth coefficient for Hencky strains corresponding to the extension thinning behavior. In this direction, the effect of clay is more evident, and it postpones the yielding related to the rotation of the cylinders to higher values of Hencky strain values, increasing the overall transient extensional viscosity. The measured Hencky strain values for the onset of extensional thinning at $0.01 \mathrm{~s}^{-1}$ for SEBS-30 and nanocomposites containing 2.5, 5, and 7.5 wt. \% clay are $0.10,0.10,0.14$, and 0.17 , respectively. The extensional thinning occurs because as the nanoparticles are inserted within the PS cylinders, the rotation of the cylinders becomes more difficult, and as a result there is an increase of initial resistance to the extensional flow. For the maleated copolymer (SEBS-30-MA), the addition of clay was felt on the full Hencky strain range as the clay was distributed within the soft PEB phase, but not in the PS cylinders. However, the overall effect on $\eta_{\mathrm{E}}^{+}$curves is less intense. For these samples, the onset of yielding, which corresponds to the start of extensional thinning occurs at a Hencky strain of about 0.21 at $0.01 \mathrm{~s}^{-1}$. This value is slightly higher than for the nonmaleated copolymer samples, and it is apparently not affected by the presence of clay. This is probably also due to the fact that in these samples the clay is not in preferential contact with the PS cylinders and can thus rotate more freely.

The rheological behavior in extensional flow in both directions (longitudinal and transverse) corroborates the data obtained previously by Carastan et al. [29]. These results can be explained as follows: (i) longitudinal direction: the rheological behavior is governed by PS cylinders that are able to slide over the PEB phase and no significant morphological change occurs during the test and (ii) transverse direction: the rheological behavior is first governed by an affine deformation of the whole multiphase system and followed by a yielding of the structure that causes the rearrangement of the PS cylinders in the stretching direction by rotation.

These rheological results are supported by the mechanical characterization performed by DMA presented in Fig. 8. It can be seen that at temperatures above the glass transition of the EB phase (around $-50^{\circ} \mathrm{C}$ ), the addition of clay only affects the storage modulus of the copolymers tested in the $\mathrm{T}$ direction [Fig. 8(b)], as the mechanical behavior is dominated by the soft EB matrix in this direction. In the L direction the mechanical properties are dominated by the stiff PS cylinders, so the presence of clay particles has little effect on $\mathrm{E}^{\prime}$ [Fig. 8(a)]. The reinforcing effect of clay particles, 
a)

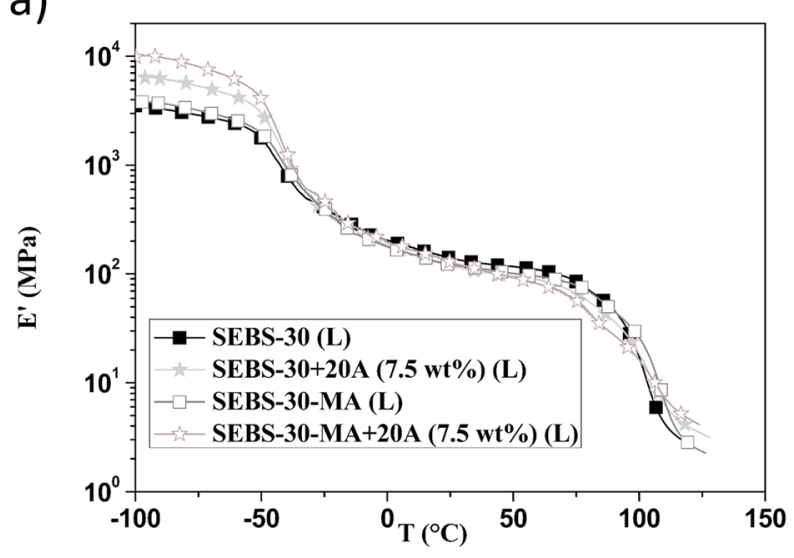

c)

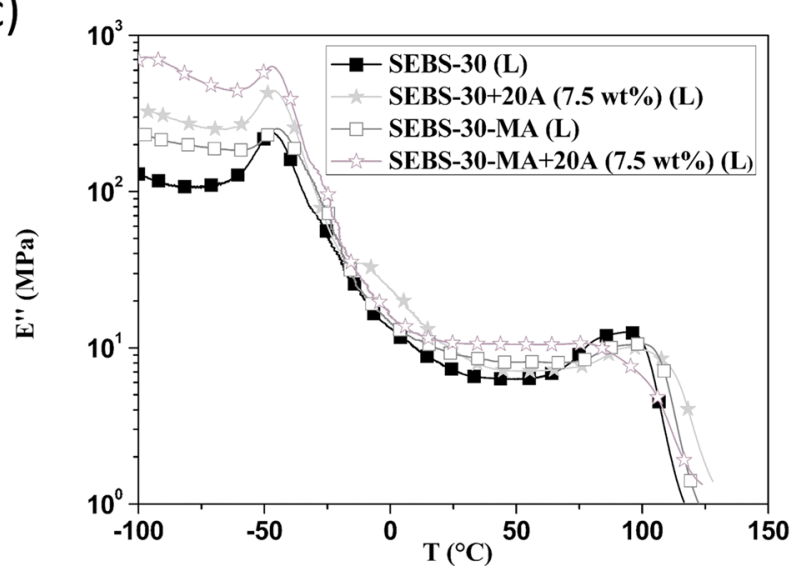

b)

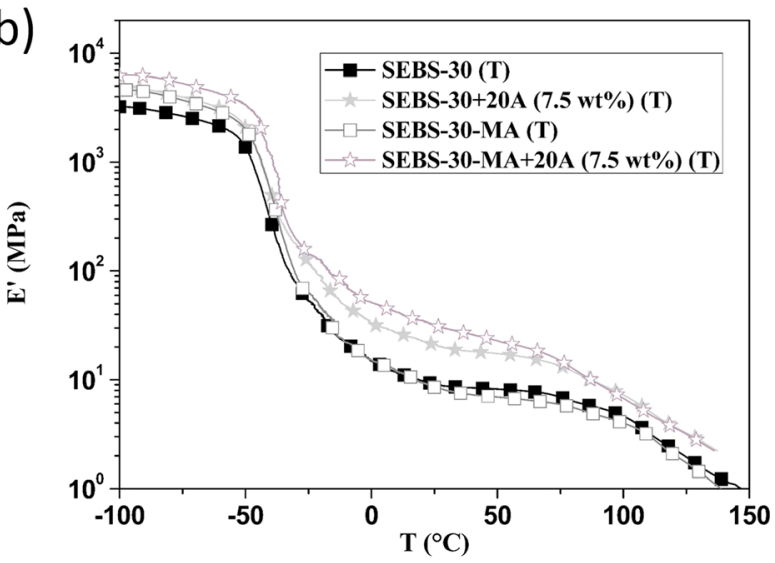

d)

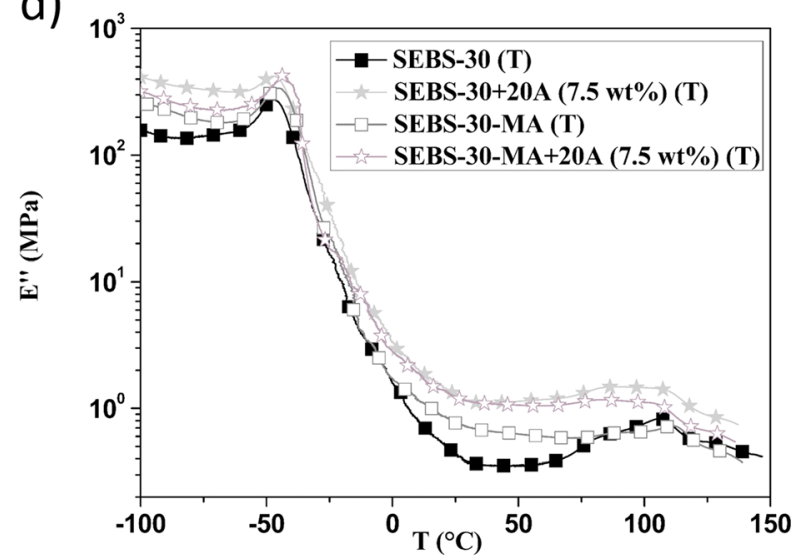

FIG. 8. Mechanical characterization performed by DMA: (a) Storage modulus $\mathrm{E}^{\prime}$ in the L direction, (b) storage modulus $\mathrm{E}^{\prime}$ in the T direction, (c) loss modulus $\mathrm{E}^{\prime \prime}$ in the L direction, and (d) loss modulus $\mathrm{E}^{\prime \prime}$ in the T direction for SEBS-30 and SEBS-30+20A (7.5 wt. \%).

however, appears at temperatures below $-50^{\circ} \mathrm{C}$, when the EB matrix goes to the glassy state.

The morphological evolution of the samples was evaluated by SAXS at several stages of elongation at Hencky

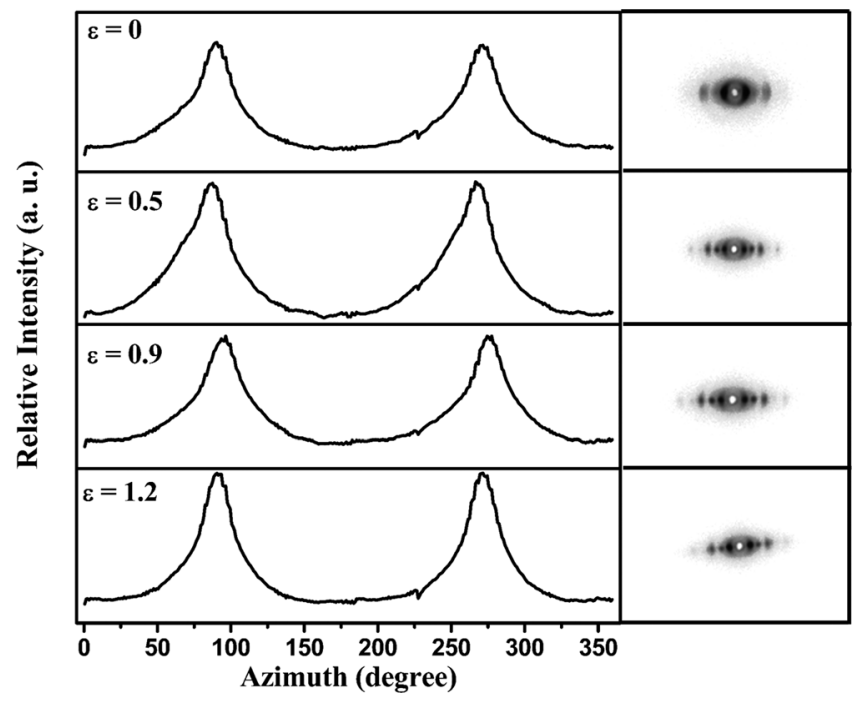

FIG. 9. Azimuthal x-ray scattering intensity distribution for the (100) Bragg peak related to the cylindrical block copolymer structure at different Hencky strain values along of the sample tested, according to Fig. 2, and their respective 2D-SAXS patterns for the SEBS-30 sample elongated in the longitudinal direction (L) at a strain rate of $0.01 \mathrm{~s}^{-1}$. strain rates of 0.01 and $20 \mathrm{~s}^{-1}$. Figure 9 shows the scattering intensity plots of the (100) peak as a function of the azimuthal angle and their corresponding 2D SAXS patterns for pure SEBS-30 elongated in the longitudinal (L) direction at a strain rate of $0.01 \mathrm{~s}^{-1}$. Similarly, Fig. 10 shows the scattering intensity plots as a function of the azimuthal angle for the SEBS-30 nanocomposites containing 2.5 and $7.5 \mathrm{wt}$. \% clay tested at $0.01 \mathrm{~s}^{-1}$. The results include both the (100) Bragg peak associated with the cylindrical block copolymer structure and the (001) peak associated with the intercalated clay structure. Only the SEBS-30 data are presented, because SEBS-30-MA samples exhibited a similar behavior.

The azimuthal curves and the 2D SAXS patterns reveal that the structure of the block copolymer remains essentially unaltered with deformation at a low rate. The cylinders are aligned in the test direction and the structure is maintained. There is only a sharpening of the peaks associated to the block copolymer structure, indicating that the cylinders become even more aligned with the elongation. In the case of the nanocomposites, the behavior is similar for the PS cylindrical domains. The clay particles, on the other hand, show significant orientation changes during the test. Initially, a diffraction halo related to the clay particles is formed, corresponding to a fraction of the clay particles that were not aligned in the $x-y$ plane. This halo is more evident at high clay concentrations. During the extensional tests, the clay 
a)
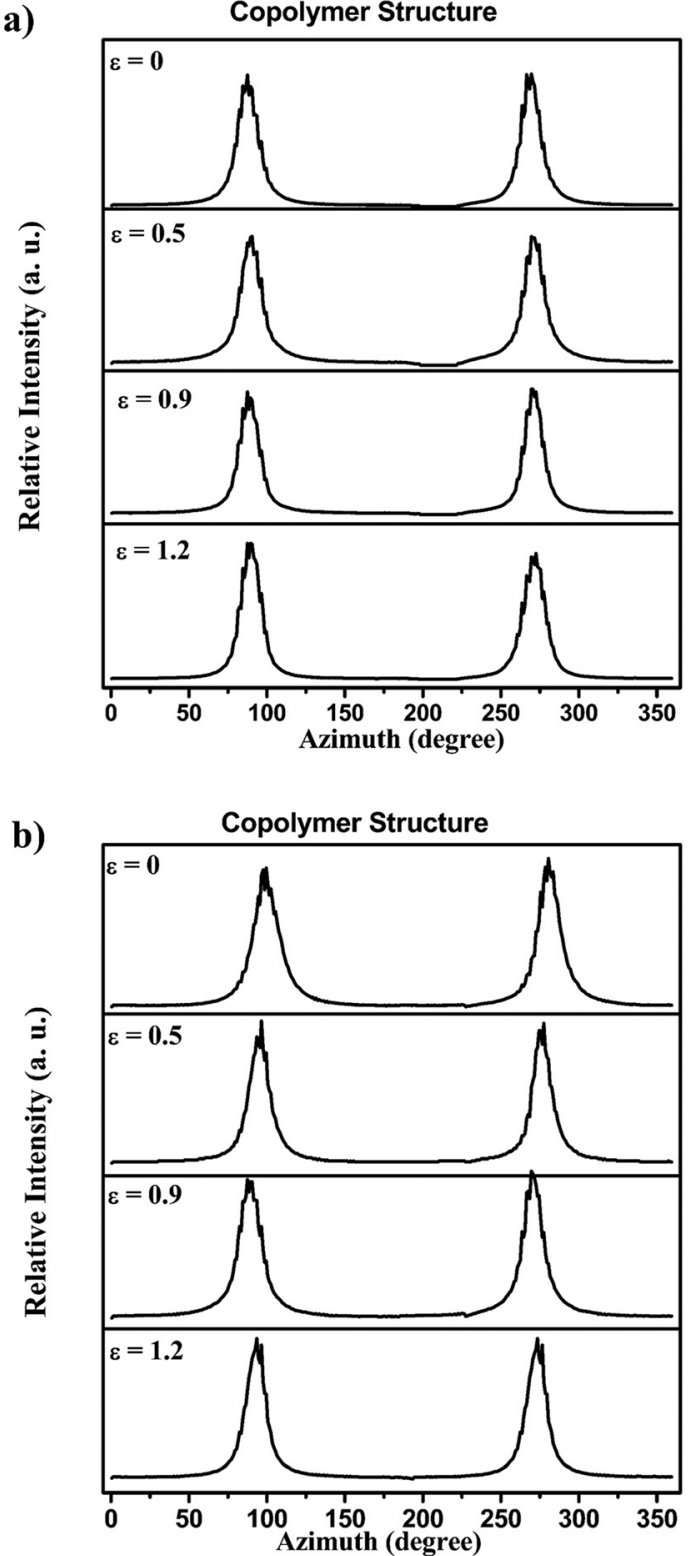
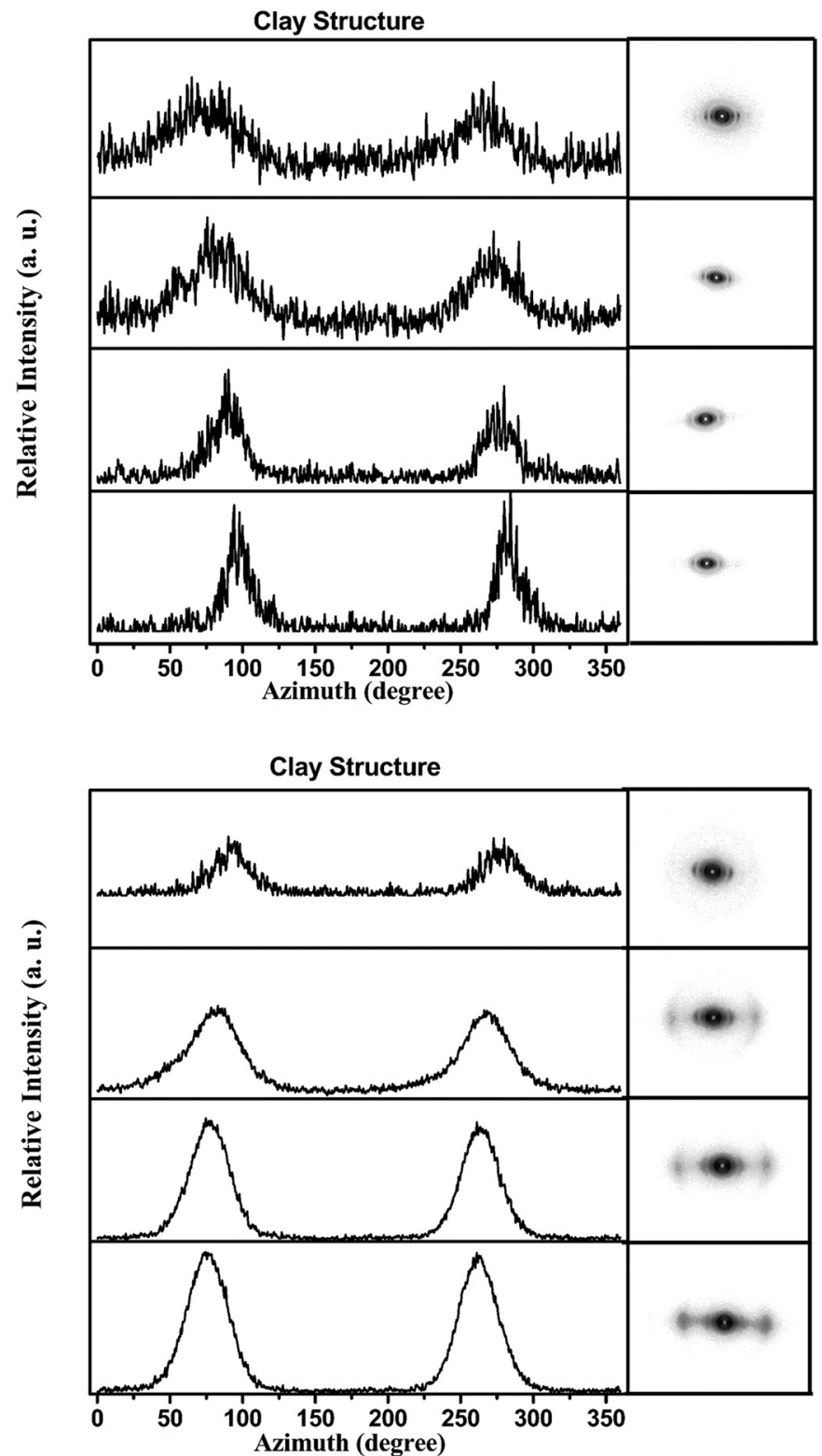

FIG. 10. Azimuthal x-ray scattering intensity distribution for the (100) peak of the block copolymer cylindrical structure and the (001) peak of the intercalated clay nanoparticles of the SEBS-30+20A nanocomposites elongated in the longitudinal direction at a strain rate of $0.01 \mathrm{~s}^{-1}$. Clay concentration: (a) 2.5 wt. \% and (b) 7.5 wt. \%. The corresponding 2D SAXS patterns are shown in the insets.

particles exhibit an increasing alignment with increasing strain, becoming parallel to the $\mathrm{x}-\mathrm{z}$ plane. This effect is seen in both strain rates analyzed (the results for $20 \mathrm{~s}^{-1}$ are not shown). This alignment of clay particles is not strong enough to be sensed by the rheological measurements for the samples containing 2.5 and 5 wt. \% clay (Fig. 6). At a higher clay content $(7.5 \mathrm{wt} . \%)$, however, there are fewer clay particles previously aligned in the extrusion direction, being required a greater effort to align the clay particles and PS cylinders, resulting in a slightly more viscous behavior during extension in the $\mathrm{L}$ direction.

In order to evaluate the degree of alignment of the PS cylinders at a strain rate of $20 \mathrm{~s}^{-1}$ the order parameter $(f)$ was calculated [39]. This parameter is an average value that correlates the direction of the PS cylinder axes which the direction of testing $(\beta)$, and it can be calculated from the azimuthal SAXS intensity distribution curves $[\mathrm{I}(\beta)]$ by the Eq. (2) [40]

$$
f=\frac{3\left(\cos ^{2} \beta\right)-1}{2}=\frac{\int I(\beta)|\sin \beta|\left(\frac{3}{2} \cos ^{2} \beta-\frac{1}{2}\right) d \beta}{\int I(\beta)|\sin \beta| d \beta} .
$$

Figure 11 shows the values of $f$ as a function of Hencky strain for SEBS-30 and its nanocomposites along the L direction at a high Hencky strain rate $\left(\dot{\varepsilon}=20 \mathrm{~s}^{-1}\right)$. The order parameter was calculated from the azimuthal scattering intensity distributions for the (100) Bragg peak associated with the cylindrical block copolymer structure. It can be seen that the samples deformed at $20 \mathrm{~s}^{-1}$ initially exhibit an increasing alignment of the cylinders, followed by a misalignment at high Hencky strains. The presence of clay at a low concentration $(2.5$ wt. \%) is apparently hindering this misalignment at high strain rates, an effect not observed in the other concentrations. 


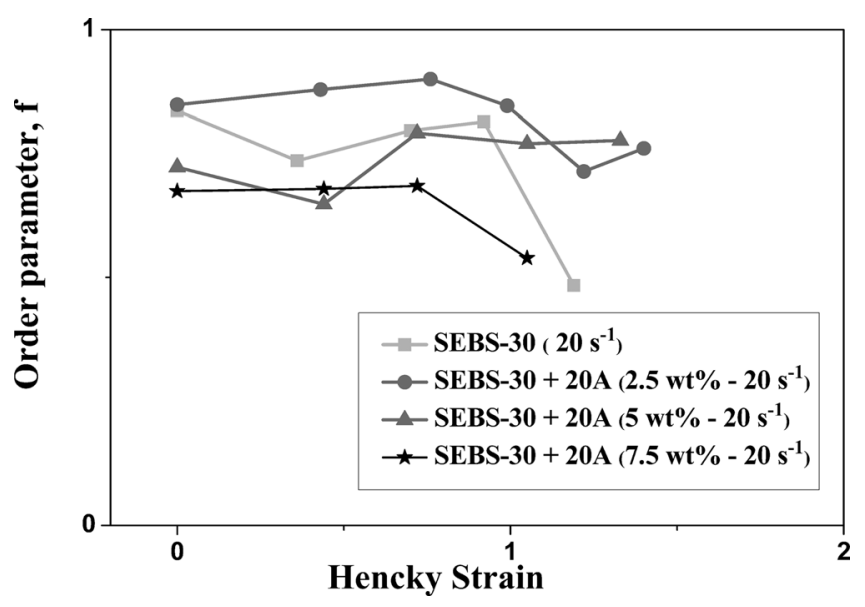

FIG. 11. SAXS order parameter (f) calculated from the azimuthal scattering intensity distribution for SEBS-30 nanocomposites elongated in the longitudinal direction at a strain rate of $20 \mathrm{~s}^{-1}$.

The cylinder misalignment may also correspond to a decrease of long-range order: Figure 12 displays the radial SAXS plots as a function of Hencky strain for SEBS-30 and its nanocomposites elongated in the longitudinal direction at a $20 \mathrm{~s}^{-1}$ strain rate. The secondary diffraction peaks become less visible at high Hencky strain values, indicating the formation of a more poorly ordered structure. However, the a)

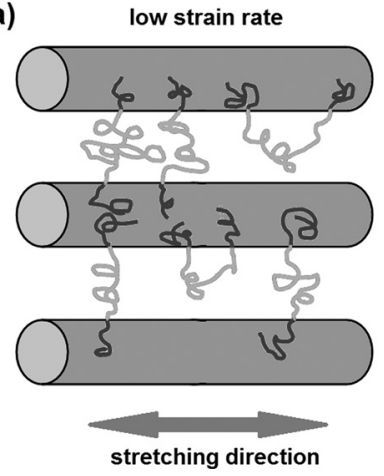

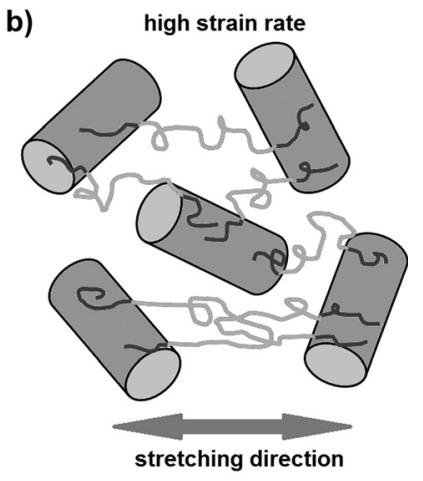

FIG. 13. Schematic diagram of cylindrical domains and block copolymer molecules after being stretched by an extensional flow in the $\mathrm{L}$ direction at (a) a low strain rate and (b) a high strain rate.

arrangement of the PS cylinders continues to be hexagonal. This behavior is related to a competition among structural features of the block copolymer at different scales [29] (see Fig. 13). On the nanoscale, the structure is composed of the copolymer ordered domains, which tend to align in the extrusion direction. On the molecular level, however, the block molecules usually remain perpendicular to the cylinder axis in order to form the structure. As the individual molecules have higher mobility/short relaxation times, deformation at low strain rates favors the alignment of the nanostructures,
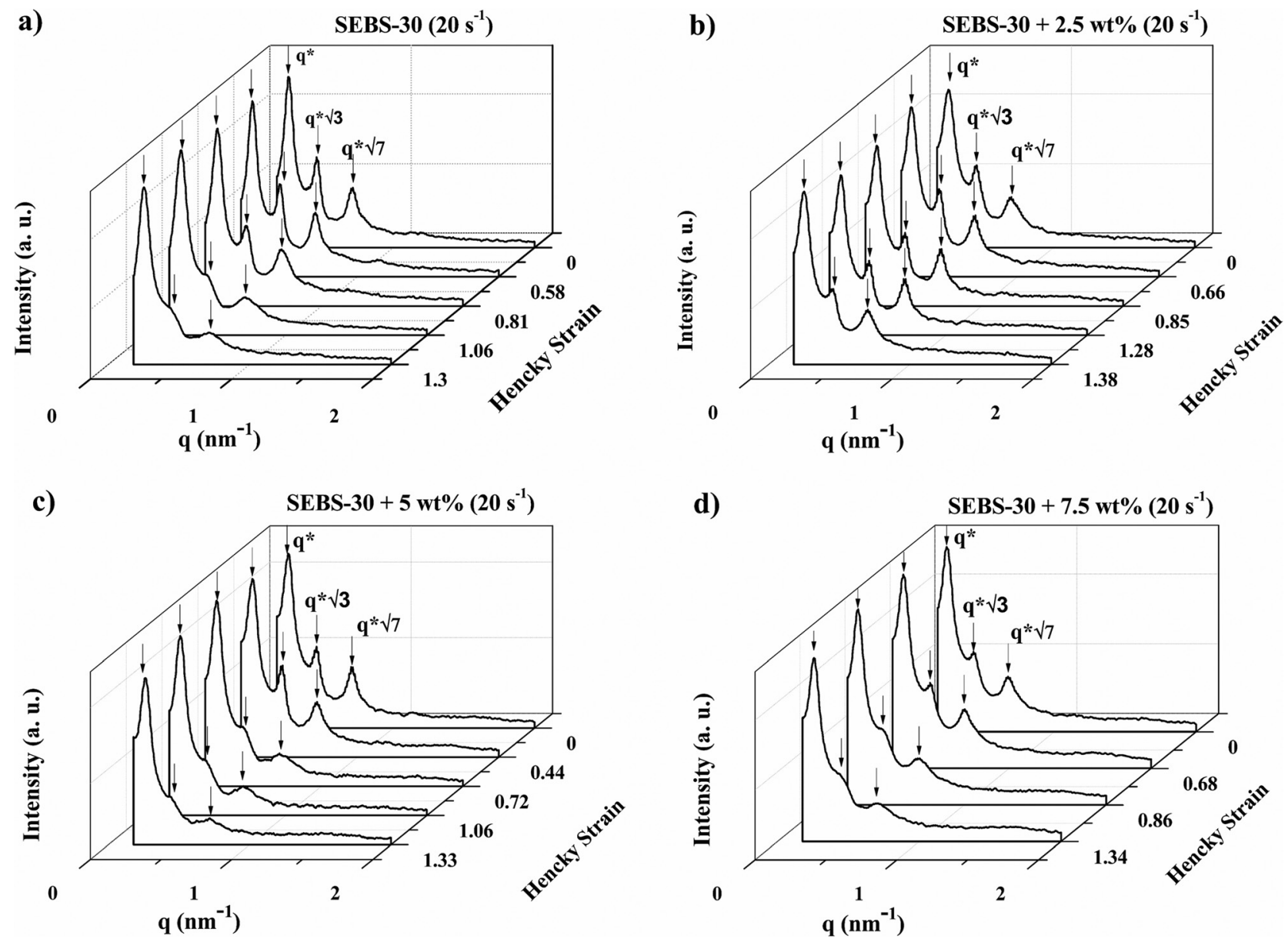

FIG. 12. 1D SAXS plots as a function of Hencky strain for samples tested in the longitudinal direction (L) at a strain rate of $20 \mathrm{~s}^{-1}$ : (a) pure SEBS-30, (b) 2.5 wt. $\% 20 \mathrm{~A}$, (c) 5 wt. $\% 20 \mathrm{~A}$, and (d) 7.5 wt. $\% 20 \mathrm{~A}$. 
a)

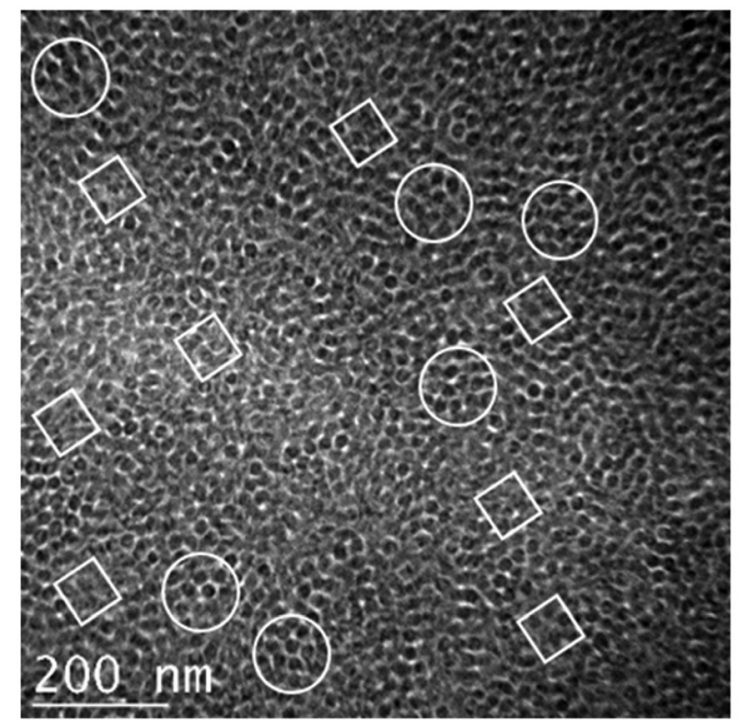

b)

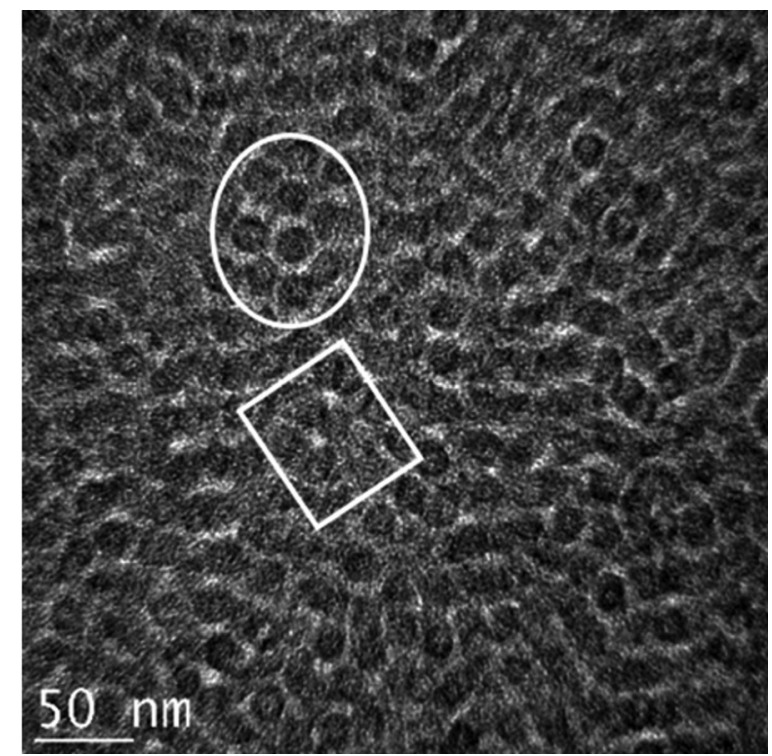

FIG. 14. TEM micrographs for SEBS-30 stretched in the $\mathrm{L}$ direction at high Hencky strain rate $\left(20 \mathrm{~s}^{-1}\right)$. The $\mathrm{x}$ direction is perpendicular to the micrographs.

and the molecules remain perpendicular to the flow [Fig. 13(a)]. When high strain rates are applied, at high Hencky strains the molecules themselves tend to align parallel to the flow, as there is not enough time for them to relax [Fig. 13(b)]. This happens at the expense of the original cylinder alignment and overall long-range order, as the cylinders probably break in shorter domains.

These hypotheses are supported by TEM observation, as shown in Fig. 14. Carastan et al. [26] reported the morphology of SEBS-30 before stretching, which exhibits a cylindrical structure perfectly aligned in the $\mathrm{x}$ direction, arranged in a nearly single-crystal-like structure. Figure 14 shows the morphology of SEBS-30 observed in the $\mathrm{x}$ direction after stretching at $20 \mathrm{~s}^{-1}$. It can be seen that after the extensional flow the samples are no longer homogeneously oriented. Even though some cylinder cross sections can still be seen arranged in local hexagonal patterns (circles), other regions show deviation from uniaxial alignment (squares). The single-crystal-like ordering has also completely disappeared.

The presence of clay nanoparticles may affect this misalignment. The diffraction peaks of the sample containing $2.5 \mathrm{wt}$. \% clay remain sharp during elongation (as shown by the constant value of the order parameter in Fig. 11), probably because the smaller tactoids are better dispersed within the copolymer. Because the clay remains in direct contact with the PS cylinders in this SEBS sample, clay particles should hinder the movement of the cylinders in another direction. In the case of the nanocomposites with higher clay loadings ( 5 and $7.5 \mathrm{wt}$. $\%$ ), the larger tactoids are not sufficiently well dispersed in the copolymer to prevent the misalignment of the cylinder.

The effects of the extensional tests on the morphological changes of the block copolymers and nanocomposites were also evaluated for the transverse direction. The azimuthal peak angle of the PS cylinder (100) Bragg peak was evaluated as a function of Hencky strain for SEBS-30, SEBS-30MA and their nanocomposites elongated in the transverse (T) direction at the strain rates of $0.01 \mathrm{~s}^{-1}$ (Fig. 15) and $20 \mathrm{~s}^{-1}$ (Fig. 16).
In general, the PS cylinders tend to align with the flow direction, i.e., rotate as extension proceeds. However, the strain at which this phenomenon starts to occur and its speed depends on the presence of clay, the state of clay dispersion, and the Hencky strain rate. The results indicate that at a strain rate of $0.01 \mathrm{~s}^{-1}$ the rotation begins at Hencky strains ranging between 0.2 and 0.5 depending on the sample. These values are qualitatively similar to the ones at the onset of yielding, as measured by the rheological tests, although they are not exactly the same. Once the yielding has occurred, the presence of clay appears to speed up the rotation process. At a Hencky strain rate of $20 \mathrm{~s}^{-1}$, the rotation of PS cylinders is not fully complete unless a larger concentration of clay is added to the copolymer.

PS cylinders perpendicular to the stretching direction are forced to get on the PEB domain, but both domains do not mingle due to their mutual immiscibility and so there can be no flow occurring unless the domains are rotated in the stretching direction. The presence of clay nanoparticles increases the viscosity during the rotation process, but the clay nanoparticles also rotate, and consequently, the reorientation of the cylindrical domains is improved. Larger clay particles have a stronger tendency to align with the cylinders mainly at high clay concentrations, as the particles are attached to the PS cylinders, and they are easily dragged alongside them. Even the clay nanoparticles, which are in contact with the PEB matrix, do not impede the reorientation of the cylinders.

At high strain rates, the incomplete rotation of the cylinders is another result of the competition between the alignment of domains and copolymer molecules (Fig. 13). The presence of higher concentrations of clay ensures complete rotation, although a decrease in the order of the domains still occurs (not shown) [29].

\section{Copolymers with isotropic structure}

Figure 17 shows the tensile stress growth coefficient for the SEBS-13 triblock copolymers (13 wt. \% PS) at different 
a)

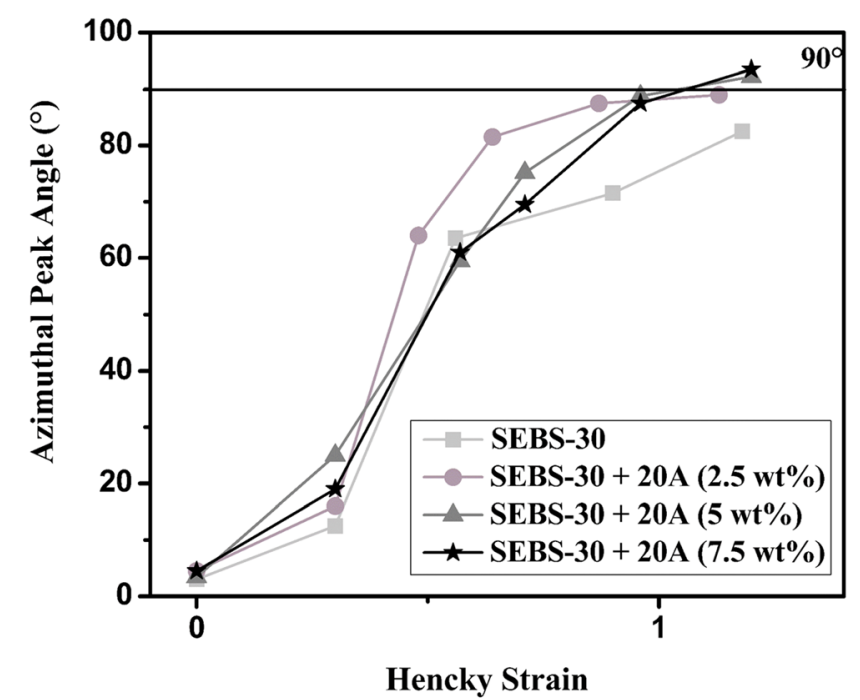

b)

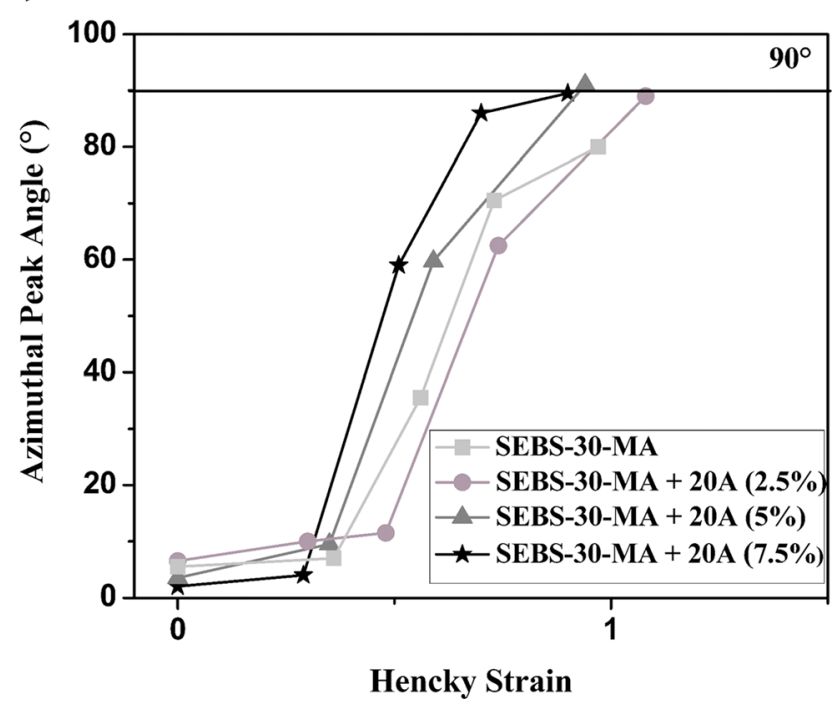

FIG. 15. Azimuthal peak angle plots from the SAXS patterns of the (100) Bragg peaks of the cylindrical structure of the copolymers and their nanocomposites elongated in the transverse direction $(\mathrm{T})$ at a low strain rate $\left(0.01 \mathrm{~s}^{-1}\right)$ : (a) SEBS-30 and (b) SEBS-30-MA.

Hencky strain rates $\left(0.01,0.1,1\right.$, and $\left.20 \mathrm{~s}^{-1}\right)$. Figure 17(a) shows the effects of the test direction for the pure copolymer (SEBS-13). Figure 17(b) compares the rheological behavior of SEBS-13 to that of the maleated copolymer (SEBS-13$\mathrm{MA}$ ) and their respective nanocomposites. It can be seen that for all the samples, the tensile stress growth coefficient increases steadily with stretching time indicating that most likely, there is no significant change in the orientation of PS cylinders occurs during stretching. The tensile stress growth coefficient is not influenced by the test direction, which is an expected result, because the block copolymers with $13 \mathrm{wt}$. \% PS present isotropic structure after extrusion, as shown in Fig. 4(b). In Fig. 17(b), we can see the triple of the shear stress growth coefficient curve $(3 \cdot \eta+)$ for the pure SEBS-13, at $\dot{\gamma}=0.001 \mathrm{~s}^{-1}$. These results indicate that Trouton's rule holds up to the onset of failure of the elongated samples. a)

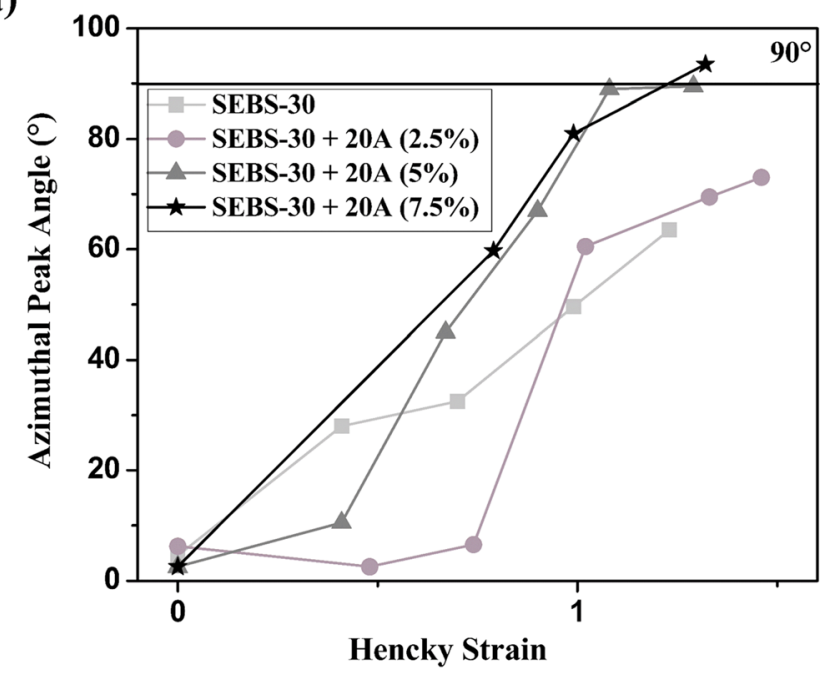

b)

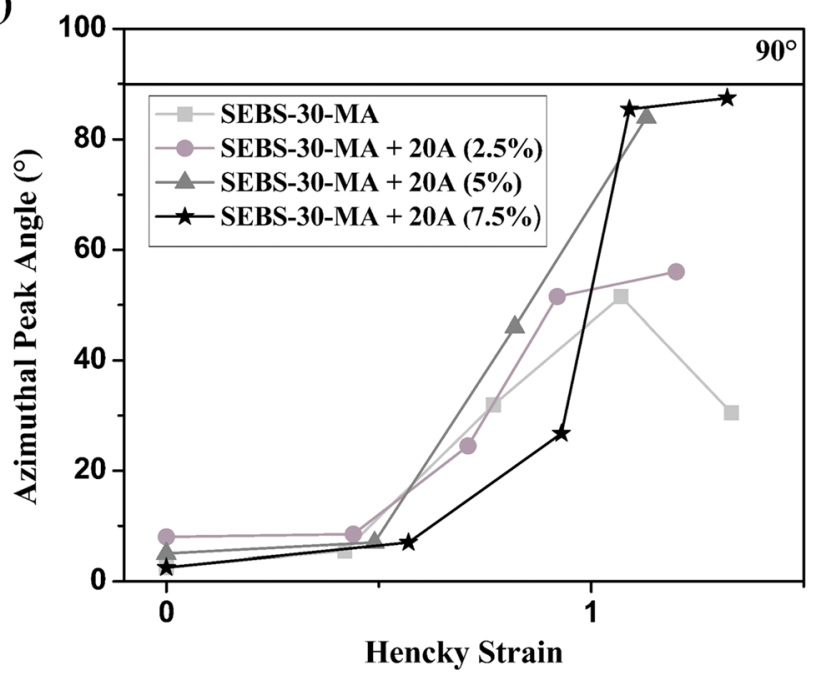

FIG. 16. Azimuthal peak angle plots from SAXS patterns of the (100) Bragg peaks of the cylindrical structure of the copolymers and their nanocomposites elongated in the transverse direction $(\mathrm{T})$ at a high strain rate $\left(20 \mathrm{~s}^{-1}\right)$ : (a) SEBS-30 and (b) SEBS-30-MA.

SEBS-13-MA is considerably less viscous than its nonmaleated counterpart, as can be seen in Fig. 17(b). While the addition of clay does not influence on the rheological behavior for SEBS-13, it however does increase the extensional viscosity of the maleated copolymer. The 2D SAXS patterns from Fig. 5 might help explain this behavior. According to Fig. 5(a), the intercalated clay particles lie essentially parallel to the tape plane. As the copolymer structure is isotropic, there is no difference in rheological behavior between the $\mathrm{L}$ and $\mathrm{T}$ directions, as clay particles are planar structures. Therefore, when the sample SEBS-13+20A is elongated, the clay particles can slide freely during the test, and as such that they do not need to rotate or disturb the flow of the block copolymer. A similar behavior could be expected from the SEBS-13-MA+20A sample, as the scattering of the nanoparticles indicates that most of the exfoliated clay platelets should also lie parallel to the tape plane. However, the clay platelets being so small, it is probable that they aligned in other directions as well, which would disturb the flow of the copolymer, increasing its extensional viscosity. This would 
a)
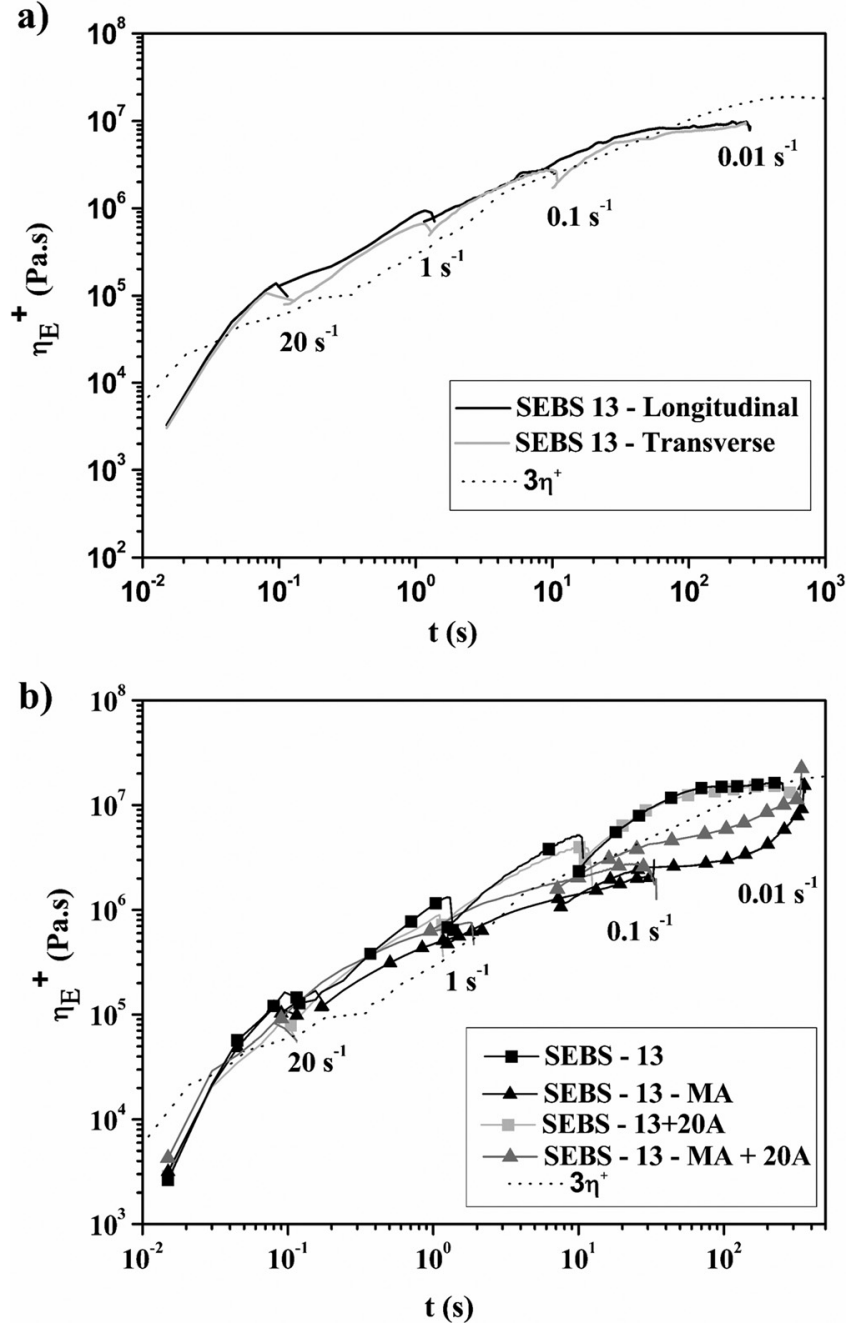

FIG. 17. Curves of steady elongation at $120^{\circ} \mathrm{C}$ for (a) SEBS- 13 in both directions and (b) SEBS-13, SEBS-13-MA and their nanocomposites in the $\mathrm{T}$ direction.

be true, especially in the case of these copolymers containing 13 wt. \% PS, which do not exhibit an anisotropic arrangement of the PS cylinders. In the case of the copolymers containing $30 \mathrm{wt}$ \% PS, because their structure was anisotropic since the beginning of the tests, their rheological behavior was dictated mostly by the cylinder structure, and the clay particles had a significant effect only at higher concentrations in the $\mathrm{T}$ direction.

The morphological evolution of these samples was also studied by SAXS. The results from the mapping (not shown) of the pure SEBS-13 and SEBS-13-MA samples after elongation at $0.01 \mathrm{~s}^{-1}$ revealed the absence of any permanent structural alignment. The addition of clay, however, resulted in a different response after elongation. Figure 18 shows the scattering intensity plots of the Bragg peak referring to the (100) plane as a function of azimuthal angle distribution for SEBS-13+20A and SEBS-13-MA+20A elongated in the transverse (T) direction, at a strain rate of $0.01 \mathrm{~s}^{-1}$. The addition of clay nanoparticles promotes a partial alignment of the cylindrical domains in both copolymers, but the effect appears to be more prominent in the nonmaleated sample.

The comparison of the different block copolymers (30 and 13 wt. \% PS) studied here is important for understanding a)

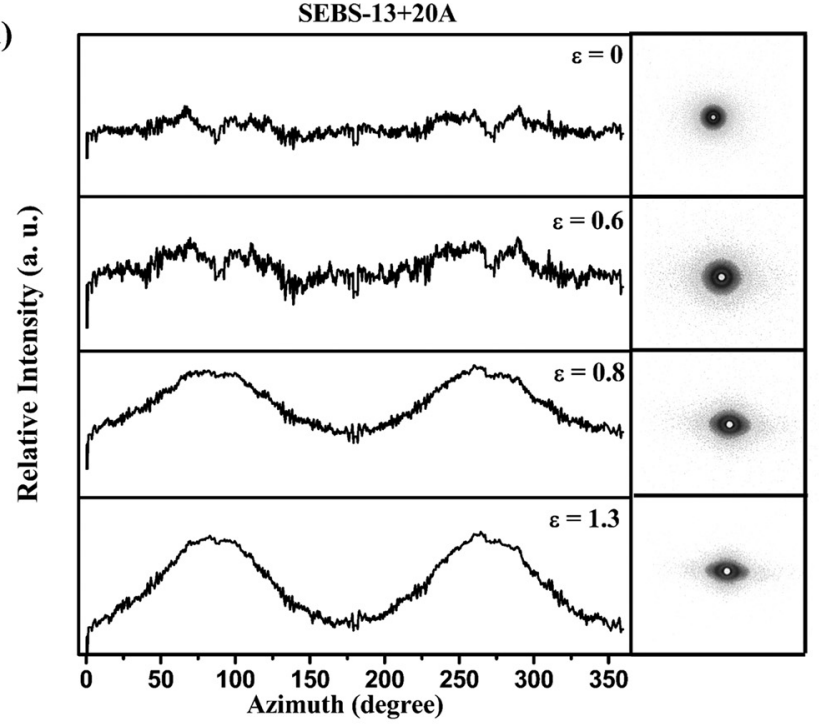

b)

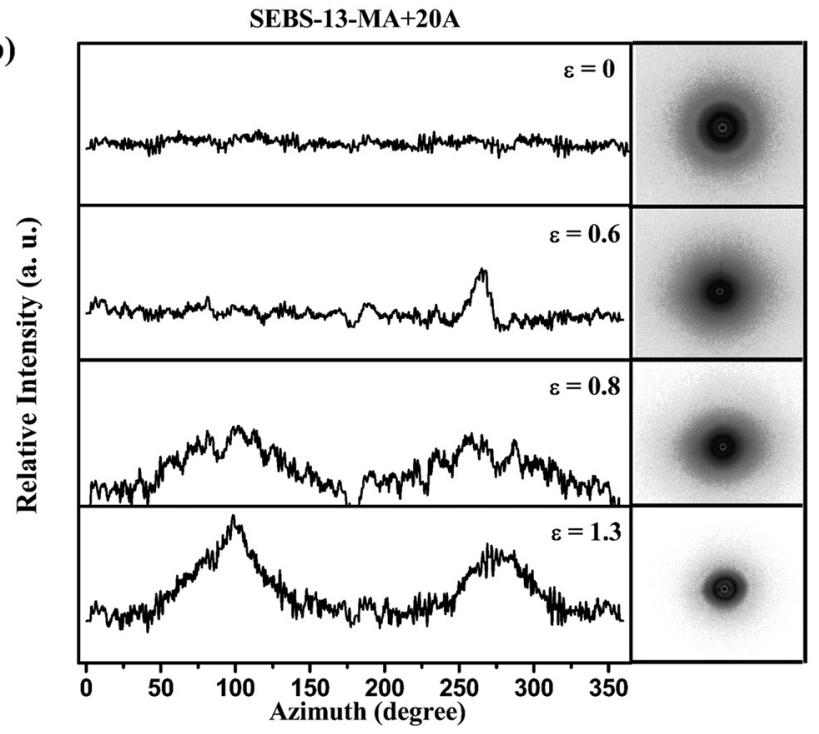

FIG. 18. Azimuthal plot from the SAXS patterns for the (100) peak of the block copolymer cylindrical structure of elongated samples along the transverse direction (T) at $0.01 \mathrm{~s}^{-1}$ : (a) SEBS-13+20A and (b) SEBS-13$\mathrm{MA}+20 \mathrm{~A}$. The corresponding 2D SAXS patterns are shown in the insets.

the distinctive microstructural features promoted by stretching. Both SEBS-30 and SEBS-13 and their maleated counterparts have cylindrical structures, but as the SAXS tests revealed, the cylinders have a better ordered structure in the SEBS-30 samples. The cylindrical domains of the SEBS-30 samples readily align with shear and/or elongation, and this alignment is maintained after flow cessation. However, in the case of the SEBS-13 copolymers, it is likely that their morphology may have changed during the cooling process. Other studies have shown that similar copolymers (SEBS-13) do exhibit an alignment of cylindrical structures under elongation, but these materials relax their structure very quickly $[27,28]$. This probably occurs due to the tendency of the materials to form spherical structures, and so the cylinders are not long or perfect enough, and they end up relaxing quickly.

The presence of clay nanoparticle does however affect this relaxation, promoting a permanent alignment of the PS domains after extensional flow cessation. As the clay 
nanoparticles align in the direction of flow, they act somewhat as templates to induce the alignment of the cylindrical domains and prevent a postflow misalignment due to relaxation. This seems to be more effective in the nonmaleated copolymer, as the clay nanoparticles are in preferential contact with the PS domains. Nevertheless, the SEBS-13-MA nanocomposite also exhibits some permanent alignment, in this case probably due to the better dispersion of the clay nanoparticles, even though they are not in direct contact with the PS domains. These anisotropic features could, however, be directly related to the scattering of aligned exfoliated clay particles instead of the cylinders. In this case, SEBS-13-MA+20A could contain some clay particles perpendicular to the $\mathrm{x}-\mathrm{y}$ plane which would rotate after stretching. Therefore, it is not possible to resolve unambiguously if the anisotropy in SEBS-13-MA+20A is caused by the PS cylinders of by clay nanoparticles. In other samples, this seems not to be a relevant issue.

\section{CONCLUSIONS}

We have studied the melt rheological properties in extensional flow of several SEBS block copolymers with cylindrical morphology and their clay-containing nanocomposites. The structure of the samples was monitored by SAXS after the extensional tests, in order to evaluate the orientation of the copolymer domains and clay nanoparticles during elongation, and so see if the latter persisted after the cessation of flow. It was shown that the rheological behavior depends on the initial morphological orientation of the copolymer domains and presence of clay nanoparticles. The anisotropic cylindrical PS domains and clay particles in the samples with long range order PS cylindrical morphology (SEBS containing $30 \mathrm{wt}$ \% PS) are easily aligned with flow, and their rheological properties are strongly affected by this effect. On the other hand, samples with small range order PS cylindrical morphology (SEBS containing 13 wt. \% PS) are isotropic, and only exhibit permanent alignment after elongation in the presence of clay. The results also showed that the relaxation of the polymer chains is greatly affected by the presence of nanoparticles.

\section{ACKNOWLEDGMENTS}

The authors would like to acknowledge Fundação de Amparo à Pesquisa (FAPESP), Coordenação de Aperfeiçoamento de Pessoal de Nível Superior (CAPES), Conselho Nacional de Desenvolvimento Científico e Tecnológico (CNPq), Natural Sciences and Engineering Research Council of Canada (NSERC), and École de technologie supérieure (ETS) for financial support, Kraton for materials supply, the Crystallography Laboratory of the Physics Institute at the University of São Paulo and the National Laboratory of Synchrotron Light in Campinas (LNLS) for the SAXS experiments.

\section{References}

[1] Ohta, T., and K. Kawasaki, "Comment on the free energy functional of block copolymer melts in the strong segregation limit," Macromolecules 23, 2413-2414 (1990).
[2] Helfand, E., "Block copolymer theory. III. Statistical mechanics of the microdomain structure," Macromolecules 8, 552-556 (1975).

[3] Semenov, A. N., "Theory of block copolymer interfaces in the strong segregation limit," Macromolecules 26, 6617-6621 (1993).

[4] Hamley, I. W., "Structure and flow behaviour of block copolymers," J. Phys.: Condens. Matter 13, R643-R671 (2001).

[5] Sakurai, S., T. Momii, K. Taie, M. Shibayama, S. Nomura, and T. Hashimoto, "Morphology transition from cylindrical to lamellar microdomains of block copolymers," Macromolecules 26, 485-491 (1993).

[6] Peter, D. O., T. M. Scott, and S. T. Milner, "Strong segregation theory of bicontinuous phases in block copolymers," Macromolecules 31, 4011-4022 (1998).

[7] Holden, G., N. R. Legge, P. Quirk, and H. E. Schroede, Thermoplastic Elastomers, 2nd ed. (Hanser, Munich, 1996).

[8] Korcz, W. H., "Styrene-ethylene butylene-styrene block copolymers: The theory and practice of one thermoplastic elastomer," in 2nd European Conference of Plastic and Rubber, Technology of Plastics and Rubber Interface (The Plastics and Rubber Institute, Brussels, Belgium, 1976), pp. 1-10.

[9] Balsamo, V., A. T. Lorenzo, A. J. Müller, T. L. M. Fraga, and V. R. Santa Quiteria, "Structure, properties and applications of ABA and ABC triblock copolymers with hydrogenated polybutadiene blocks," in Block Copolymers in Nanoscience (Wiley, New York, 2008), Chap. 16, pp. 367-389.

[10] Pester, C. W., K. Schmidt, C. Liedel, K. A. Schindler, and A. Böker, "Piezoelectric properties of non-polar block copolymers," Adv. Mater. 23, 4047-4052 (2011).

[11] Toprakci, H. A. K., S. K. Kalanadhabhatla, R. J. Spontak, and T. K. Ghosh, "Polymer nanocomposites containing carbon nanofibers as soft printable sensors exhibiting strain-reversible piezoresistivity," Adv. Funct. Mater. 23, 5536-5542 (2013).

[12] Ramadan, K. S., D. Sameoto, and S. Evoy, "A review of piezoelectric polymers as functional materials for electromechanical transducers," Smart Mater. Struct. 23, 1-26 (2014).

[13] Shankar, R., T. K. Ghoshc, and R. J. Spontak, "Dielectric elastomers as next-generation polymeric actuators," Soft Matter 3, 1116-1129 (2007).

[14] Koo, C. M., "Electroactive thermoplastic dielectric elastomers as a new generation polymer actuators," in Thermoplastic Elastomers (INTECH Open Access Publisher, South Korea, 2012), pp. 399-416.

[15] Brochu, P., and Q. Pei, "Advances in dielectric elastomers for actuators and artificial muscles," Macromol. Rapid Commun. 31, 10-36 (2010).

[16] Kim, H.-C., S.-M. Park, and W. D. Hinsberg, "Block copolymer based nanostructures: Materials, processes, and applications to electronics," Chem. Rev. 110, 146-177 (2010).

[17] Helal, E., N. R. Demarquette, L. G. Amurin, E. David, D. J. Carastan, and M. Fréchette, "Styrenic block copolymer-based nanocomposites: Implications of nanostructuration and nanofiller tailored dispersion on the dielectric properties," Polymer 64, 139-152 (2015).

[18] Vaia, R. A., and E. P. Giannelis, "Polymer melt intercalation in organically-modified layered silicates: Model predictions and experiment," Macromolecules 30, 8000-8009 (1997).

[19] Dennis, H. R., D. L. Hunter, D. Chang, S. Kim, J. L. White, J. W. Cho, and D. R. Paul, "Effect of melt processing conditions on the extent of exfoliation in organoclay-based nanocomposites," Polymer $\mathbf{4 2}$, 9513-9522 (2001).

[20] Saito, T., M. Okamoto, R. Hiroi, M. Yamamoto, and T. Shiroi, "Delamination of organically modified layered filler via solid-state processing," Macromol. Rapid Commun. 27, 1472-1475 (2006). 
[21] Carastan, D. J., and N. R. Demarquette, "Polystyrene/clay nanocomposites," Int. Mater. Rev. 52, 345-380 (2007).

[22] Ray, S. S., and M. Okamoto, "Polymer/layered silicate nanocomposites: A review from preparation to processing," Prog. Polym. Sci. 28, 1539-1641 (2013).

[23] Folkes, M. J., and A. Keller, "Optical and swelling properties of macroscopic "single crystals" of an S-B-S copolymer. I. Samples possessing a lamellar morphology," J. Polym. Sci. B: Polym. Phys. 14, 833-846 (1976).

[24] Pakula, T., K. Saijo, H. Kawai, and T. Hashimoto, "Deformation behavior of styrene-butadiene-styrene triblock copolymer with cylindrical morphology," Macromolecules 18, 1294-1302 (1985).

[25] Silva, A. S., C. A. Mitchell, M. F. Tse, H.-C. Wang, and R. Krishnamoorti, "Templating of cylindrical and spherical block copolymer microdomains by layered silicates," J. Chem. Phys. 115, 7166-7174 (2001).

[26] Carastan, D. J., L. G. Amurin, A. F. Craievich, M. C. Gonçalves, and N. R. Demarquette, "Clay-containing block copolymer nanocomposites with aligned morphology prepared by extrusion,” Polym. Int. 63, 184-194 (2013a).

[27] Mao, R., E. M. McCready, and W. R. Burghardt, "Structural response of an ordered block copolymer melt uniaxial extensional flow," Soft Matter 10, 6198-6207 (2014).

[28] McCready, E. M., and W. R. Burghardt, "In situ studies of structure relaxation of an ordered block copolymer melt following cessation of uniaxial extensional flow," Macromolecules 48, 264-271 (2015).

[29] Carastan, D. J., L. G. Amurin, A. F. Craievich, M. C. Gonçalves, and N. R. Demarquette, "Morphological evolution of oriented claycontaining block copolymer nanocomposites under elongational flow," Eur. Polym. J. 49, 1391-1405 (2013b).

[30] Publication Number SER-HV-P01_IM2005A (C)2005 Xpansion Instruments, LLC, Universal Testing Platform Instrument Manual (Xpansion Instruments, Tallmadge, Ohio, 2005), Chap. 1.
[31] Okamoto, M., A. Kojima, and T. Kotaka, "Elongational flow and birefringence of low density polyethylene and its blends with ultrahigh molecular weight polyethylene," Polymer 39, 2149-2153 (1998).

[32] Kano, Y., M. Okamoto, and T. Kotak, "Elongational flow birefringence of poly(methyl methacrylate)/poly(vinylidene fluoride-co-hexafluoro acetone) blends," Polymer 40, 2459-2463 (1999).

[33] Kim, Y. H., M. Okamoto, T. Kotaka, T. Ougizawa, T. Tchi, and T. Inoue, "Phase structure development in poly(styrene-co-acrylonitrile)/ poly(methyl methacrylate) blend under elongational flow," Polymer 41, 4747-4749 (2000).

[34] Kotaka, T., M. Okamoto, A. Kojima, Y. K. Kwon, and S. Nojima, "Elongational flow-induced morphology change of block copolymers: Part 1. A polystyrene-block-poly(ethylene butylene)-block-polystyreneblock-poly(ethylene butylene) tetrablock copolymer with polystyrene spherical microdomains," Polymer 42, 1207-1217 (2001).

[35] Sentmanat, M. L., "Miniature universal testing platform: From extensional melt rheology to solid-state deformation behaviour," Rheol. Acta 43, 657-669 (2004).

[36] Carastan, D. J., A. Vermogen, K. Masenelli-Varlot, and N. R. Demarquette, "Quantification of clay dispersion in nanocomposites of styrenic polymers," Polym. Eng. Sci. 50, 257-267 (2010).

[37] Vaia, R. A., and W. Liu, "X-ray powder diffraction of polymer/layered silicate nanocomposites: Model and practice," J. Polym. Sci. B: Polym. Phys. 40, 1590-1600 (2002).

[38] Vaia, R. A., K. D. Jandt, E. J. Kramer, and E. P. Giannelis, "Kinetics of polymer melt intercalation," Macromolecules 28, 8080-8085 (1995).

[39] Lee, K. M., and C. D. Han, "Linear dynamic viscoelastic properties of functionalized block copolymer/organoclay nanocomposites," Macromolecules 36, 804-815 (2003).

[40] Stasiak, J., M. R. Mackley, A. M. Squires, V. Castelletto, I. W. Hamley, and G. D. Moggridge, "Dynamics of shear-induced orientation transitions in block copolymers," Soft Matter 6, 1941-1947 (2010). 